\title{
Numerical Simulation for Fracture Propagation in Elastoplastic Formations
}

\author{
Yafei Hu $\mathbb{D}^{1},{ }^{1}$ Jin Zhao $\mathbb{D},{ }^{2}$ Lihu Cao, ${ }^{3}$ Jinzhou Zhao, ${ }^{4}$ Junshi Li, ${ }^{5}$ Zhiying Wu, ${ }^{6}$ \\ and Jianfeng Hou ${ }^{1}$ \\ ${ }^{1}$ PetroChina Research Institute of Petroleum Exploration \& Development, Beijing 100083, China \\ ${ }^{2}$ School of Mechanical Engineering, Yangtze University, Jingzhou, 434023, China \\ ${ }^{3}$ Oil \& Gas Engineering Research Institute of PetroChina Tarim Oilfield Company, Korla, Xinjiang S41000, China \\ ${ }^{4}$ State Key Laboratory of Oil and Gas Reservoir Geology and Exploitation, Southwest Petroleum University, Chengdu 610500, China \\ ${ }^{5}$ Petrochina Consulting Center, Beijing 100120, China \\ ${ }^{6}$ Reservoir Reconstruction Department of SRIPE, Beijing 100101, China
}

Correspondence should be addressed to Jin Zhao; 1642476193@qq.com

Received 30 October 2020; Revised 22 June 2021; Accepted 1 August 2021; Published 26 August 2021

Academic Editor: Jinze Xu

Copyright ( $) 2021$ Yafei Hu et al. This is an open access article distributed under the Creative Commons Attribution License, which permits unrestricted use, distribution, and reproduction in any medium, provided the original work is properly cited.

\begin{abstract}
Current hydraulic fracture models are mainly based on elastic theories, which fail to give accurate prediction of fracture parameters in plasticity formation. This paper proposes a fluid-solid coupling model for fracture propagation in elastoplastic formations. The rock plastic deformation in the model satisfies the Mohr-Coulomb yield criterion and plastic strain increment theory. The extended finite-element method (XFEM) combined with the cohesive zone method (CZM) is used to solve the coupled model. The accuracy of the model is validated against existing models. The effects of stress difference, friction angle, and dilation angle on fracture shape (length, width), injection pressure, plastic deformation, induced stress, and pore pressure are investigated through the model. The results indicate that compared with elastic formation, fracture propagation in elastoplastic formation is more difficult, the breakdown pressure and extending pressure are greater, and fracture shape is wider and shorter. The plastic deformation causes the fracture tip to become blunt. Under the condition of high stress difference or low friction angle formation, it is prone to occur large plastic deformation zones and form wide and short fracture. Compared with friction angle, dilation angle is less sensitive to plastic deformation, fracture parameters, and fracture geometry. For the formation with high stress difference and friction angle, the effect of plasticity deformation on fracture propagation should not be ignored.
\end{abstract}

\section{Introduction}

With the increasing energy consumption, efficient development of oil and gas resources has become the focus of attention. Hydraulic fracturing (HF), as a widely used technology, has become increasingly important in oil and gas stimulation $[1,2]$. Studying fracture propagation mechanism has a great significance for fracture parameter (width, length, height) optimization. The classical fracture propagation models treat formation as an elastic medium without considering the plasticity effects and fluid-solid coupling [3-8]. However, plastic failure usually occurs in soft layer or unconsolidated formation with high temperature and pressure during fracturing [9-11].
Various experiments have been conducted to study fracture propagation in soft rocks. The results indicate that with the increase of confining pressure, the rock property gradually appears plastic character, which has great influence on fracture pressure and fracture shape [12-16]. Complex fractures and fluid lag near the fracture can be also observed in soft rock during fracturing. Initiation pressure and fracture width are also affected by the confining stresses in unconsolidated formation [17-21]. Owing to rock plasticity and strong fluid-solid coupling, traditional fracture propagation models fail to accurately predict the fracture parameters in soft formation.

Previous studies on the effect of plasticity in HF were just based on static fracture and constant injection pressure in 
fracture without considering the coupling between the pressure diffusion and rock deformation. Papanastasiou [22-24] proposed that plastic yielding was affected by rock dilation, stress difference, and the cohesive zone and utilized the Mohr-Coulomb criterion to study the effect of pore pressure and permeability on fracture parameters without considering the fluid-solid coupling in porous formation. Zaki et al. [25] used the cam-clay model to assess the influence of rock plasticity on fracture volumes based on the simple models that would rely in using lower modulus or higher fracture toughness to account for plasticity. Wang et al. [26] proposed the poroelastic HF model in brittle and ductile formations. Liu et al. [27] established fracture propagation model based on the Drucker-Prager yield criterion. Lin et al. [28] investigated the effect of Young's model, Poisson's ratio, and injection rate on fracture propagation based on the modified cam-clay model. However, the influence of rock plasticity on the pore pressure and induced stress distribution and the effect of rock friction angle, dilation angle, and principal stress difference on fracture propagation based on fluid-solid coupling have not been considered in the above studies. Therefore, it is necessary to establish a fluid-solid coupling elastoplastic model for fracture propagation.

In this study, a fluid-solid coupling elastoplasticity HF model is proposed. The rock plastic deformation conforms to the Mohr-Coulomb criterion and plastic strain increment theory. Fluid flow within the fracture follows the mass conservation law. The fracture propagation criterion is based on the traction/separation law of cohesive element. By combining the extended finite-element method (XFEM) and the cohesive zone method (CZM), the Abaqus 6.14 software has been utilized to simulate fracture initiation and growth in elastoplastic formation. The simulation results are also compared with existing fracture expansion models. Meanwhile, the influences of principal stress difference, friction angle, and dilation angle on fracture length, width, injection pressure, plastic deformation, pore pressure, and induced stress have been further investigated.

\section{Mathematical Model}

Fracture propagation involves rock deformation, rock failure, fluid flowing in fracture and formation, the dynamic variation of pore pressure, and induced stress, which are a very complex process and involve multiple coexisting and interdependent subprocesses [29]. In addition, formation heterogeneity and plasticity make modeling more complex. In order to simplify the process of crack propagation, the following assumptions are made:

(1) Formation is a homogeneous, porous elastic-plastic rock medium

(2) Fracture extending without proppant transport

(3) Fluid flows within the fracture existing fluid leakoff

(4) Fluid flows through the formation in accordance with the Darcy law
2.1. Fluid-Solid Coupling Equation of Rock Deformation. Based on the above assumptions, rock deformation conforms to pore-elastoplastic theory. According to the stress balance equation, the stress equilibrium, strain displacement, and strain-stress equations can be written as follows [30]:

$$
\left\{\begin{array}{l}
d \sigma_{i j, j}+d f_{i}=0, \\
d \varepsilon_{i j}=\frac{1}{2}\left(d u_{i, j}+d u_{j, i}\right), \\
d \sigma_{i j}=D_{i j k l}^{e p} d \varepsilon_{k l},
\end{array}\right.
$$

where $d \sigma_{i j}$ is the stress increment, $d \varepsilon_{i j}$ is the strain increment, $d u_{i, j}$ is the medium displacement increment, $d f_{i}$ is the body force increment, and Dep ijkl is the elastic-plastic coefficient matrix.

The displacement and stress at the outer boundary and fluid pressure at the fracture surface are [31]

$$
\begin{cases}d u=d u *, & \text { on } \Gamma_{u}, \\ d \sigma \bullet n=d t *, & \text { on } \Gamma_{t}, \\ d n^{T}(\sigma \bullet n)=-d p, & \text { on } \Gamma_{c r}\end{cases}
$$

where $\Gamma_{u}, \Gamma_{t}$, and $\Gamma_{c r}$ are the displacement boundary condition, stress boundary condition, and fracture pressure boundary condition, respectively; $u^{*}$ and $t^{*}$ are the corresponding displacement and stress increment on the boundary; and $d p$ is fluid pressure increment on the fracture.

2.2. The Elastic-Plastic Increment Constitutive Model. When the rock begins to occur plastic failure, the strain increment of the rock is composed of elastic strain increment and plastic strain [32]:

$$
d \varepsilon_{i j}=d \varepsilon_{i j}^{e}+d \varepsilon_{i j}^{p}
$$

The elastic strain increment $d \varepsilon e$ ij and the stress increment $d \sigma_{i j}$ satisfy the Hooke's law:

$$
d \sigma_{i j}=D_{i j k l}^{e} d \varepsilon_{k l}^{e}
$$

The plastic strain increment follows the flow rule, which is defined as [33]:

$$
d \varepsilon_{i j}^{p}=\lambda \frac{\partial F}{\partial \sigma_{i j}}
$$

In the process of plastic deformation, the yield surface of the rock is a function of strengthening parameters, plastic strain, and stress [32]:

$$
\begin{aligned}
F & =F\left(\sigma_{i j}, \varepsilon_{i j}^{p}, \kappa\right), \\
d F & =\frac{\partial F}{\partial \sigma_{i j}} d \sigma_{i j}+\frac{\partial F}{\partial \kappa} d \kappa+\frac{\partial F}{\partial \varepsilon_{i j}^{p}} d \varepsilon_{i j}^{p}=0,
\end{aligned}
$$


where $\varepsilon_{i j}$ is the total strain, $\varepsilon e I j$ is the elastic strain, $\varepsilon p I j$ is the plastic strain, $\sigma_{i j}$ is the stress tensor, De $i j k l$ is the elastic constitutive tensor, $F$ is the load surface equation, $\kappa$ is the strengthening parameter of rock, and $\lambda$ is a quantity related to the slope of the uniaxial curve of stress $\sigma$-plastic strain $\varepsilon^{p}$, which can be determined by yield criteria and strengthening theory.

The stress increment is obtained by substituting equation (4) into (3).

$$
d \sigma_{i j}=D_{i j k l}^{e}\left(d \varepsilon_{k l}-d \varepsilon_{k l}^{p}\right) .
$$

Multiplying both sides of equation (8) by $\partial F / \partial \sigma_{i j}$ and substituting it into equation (7):

$$
\frac{\partial F}{\partial \sigma_{i j}} D_{i j k l}^{e}\left(d \varepsilon_{k l}-d \varepsilon_{k l}^{p}\right)=-\frac{\partial F}{\partial \kappa} d \kappa^{-} \frac{\partial F}{\partial \varepsilon_{i j}^{p}} d \varepsilon_{i j}^{p} .
$$

The hardening parameter is a function of the equivalent plastic strain and temperature, which is determined as [32]:

$$
\begin{aligned}
\frac{\partial F}{\partial \kappa} d \kappa & =\frac{\partial F}{\partial \kappa}\left(\frac{\partial \kappa}{\partial \bar{\varepsilon}^{p}} d \bar{\varepsilon}^{p}+\frac{\partial \kappa}{\partial T} d T\right)=\frac{\partial F}{\partial \kappa}\left(\frac{\partial \kappa}{\partial \bar{\varepsilon}^{p}}+\frac{\partial \kappa}{\partial T} \frac{\partial T}{\partial \bar{\varepsilon}^{p}}\right) d \bar{\varepsilon}^{p} \\
& =\frac{\partial F}{\partial \kappa}\left(\frac{\partial \kappa}{\partial \bar{\varepsilon}^{p}}+\frac{\partial \kappa}{\partial T} \frac{\partial T}{\partial \bar{\varepsilon}^{p}}\right) \frac{d \bar{\varepsilon}^{p}}{d \bar{\varepsilon}_{i j}^{P}} d \bar{\varepsilon}_{i j}^{P}
\end{aligned}
$$
follows:

The equivalent plastic strain increment is defined as

$$
\begin{aligned}
d \bar{\varepsilon}^{p}= & {\left[\frac{2}{3} d \varepsilon_{i j}^{P} d \varepsilon_{i j}^{P}\right]^{1 / 2}=\frac{\sqrt{2}}{3}\left\{\left(d \varepsilon_{x}^{P}-d \varepsilon_{y}^{P}\right)^{2}+\left(d \varepsilon_{y}^{P}-d \varepsilon_{z}^{P}\right)^{2}\right.} \\
& \left.+\left(d \varepsilon_{z}^{P}-d \varepsilon_{x}^{P}\right)^{2}+\frac{3}{2}\left[\left(\mathrm{~d} \gamma_{x y}^{P}\right)^{2}+\left(\mathrm{d} \gamma_{y z}^{P}\right)^{2}+\left(\mathrm{d} \gamma_{x z}^{P}\right)^{2}\right]\right\}^{1 / 2},
\end{aligned}
$$

where ${ }^{-} \varepsilon^{P}$ is the equivalent plastic strain; $T$ is the temperature; $\varepsilon p x, \varepsilon p y$, and $\varepsilon p z$ are the plastic strain on the $x, y$ and $z$ axis, respectively; and $\gamma p x y, \gamma p y z$, and $\gamma p x z$ are the shear stress component.

Substituting equation (10) and equation (5) into equation (9).

$$
\lambda=\frac{\left(\partial F / \partial \sigma_{i j}\right) D_{i j k l}^{e} d \varepsilon_{k l}}{A},
$$

where

$$
A=\left[\frac{\partial F}{\partial \sigma_{i j}} D_{i j k l}^{e}-\frac{\partial F}{\partial \kappa}\left(\frac{\partial \kappa}{\partial \bar{\varepsilon}^{p}}+\frac{\partial \kappa}{\partial T} \frac{\partial T}{\partial \bar{\varepsilon}^{p}}\right) \frac{d \bar{\varepsilon}^{p}}{d \bar{\varepsilon}_{i j}^{P}}-\frac{\partial F}{\partial \varepsilon_{k l}^{p}}\right] \frac{\partial F}{\partial \sigma_{k l}} .
$$

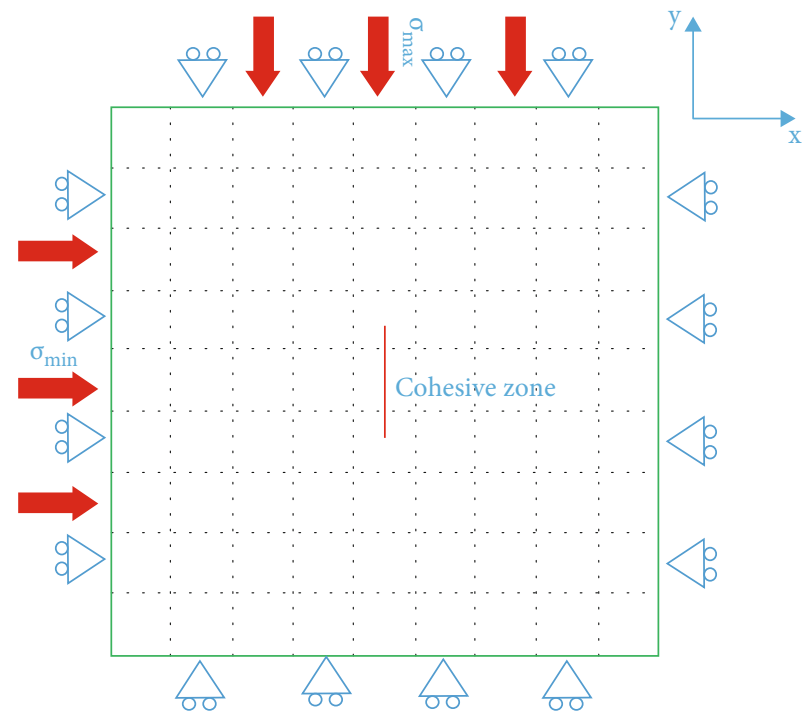

FIGURE 1: Geological model for hydraulic fracture simulation.

TABLE 1: Input parameters for hydraulic fracture model.

\begin{tabular}{lc}
\hline Properties & Value \\
\hline Young modulus (MPa) & 15000 \\
Poisson ratio & 0.25 \\
Material cohesion (MPa) & 1.5 \\
Material friction angle $\left(^{\circ}\right)$ & 28 \\
Material dilation angle $\left(^{\circ}\right)$ & 28 \\
Formation permeability coefficients $(\mathrm{m} / \mathrm{s})$ & $1 \times 10^{-7}$ \\
Maximum horizontal stress $(\mathrm{MPa})$ & 20 \\
Minimum horizontal stress $(\mathrm{MPa})$ & 15 \\
Porosity & 0.1 \\
Fluid viscosity $(\mathrm{cp})$ & 1 \\
Specific weight of fluid $\left(\mathrm{KN} / \mathrm{m}^{3}\right)$ & 9.8 \\
Initial pore pressure $(\mathrm{MPa})$ & 0.1 \\
Injection rate $\left(\mathrm{m}^{3} / \mathrm{s}\right)$ & $5 \times 10^{-3}$ \\
Pressure dependent leakoff coefficient $\left(\mathrm{m}^{3} / \mathrm{MPa} . \mathrm{s}\right)$ & $1 \times 10^{-14}$ \\
Critical fracture energy $\left(\mathrm{KN} / \mathrm{m}^{3}\right)$ & 28 \\
Damage initiation stress $(\mathrm{MPa})$ & 0.32 \\
\hline
\end{tabular}

Substituting equations (12) and (13) into equation (3) and then substituting equation (5) into equation (8), the elastic-plastic matrix can be obtained.

$$
d \sigma_{i j}=D_{i j k l}^{e p} d \varepsilon_{k l},
$$

$$
D_{i j k l}^{e p}=D_{i j k l^{-}}^{e} \frac{D_{i j k l}^{e}\left[\left(\partial F / \partial \sigma_{p q}\right)\left(\partial F / \partial \sigma_{r s}\right) D_{p q r s}^{e}\right]}{A} .
$$

2.3. Plastic Yield Criteria for Rocks. Rock deformation obeys the Mohr-Coulomb yield criterion, and we stipulate that 


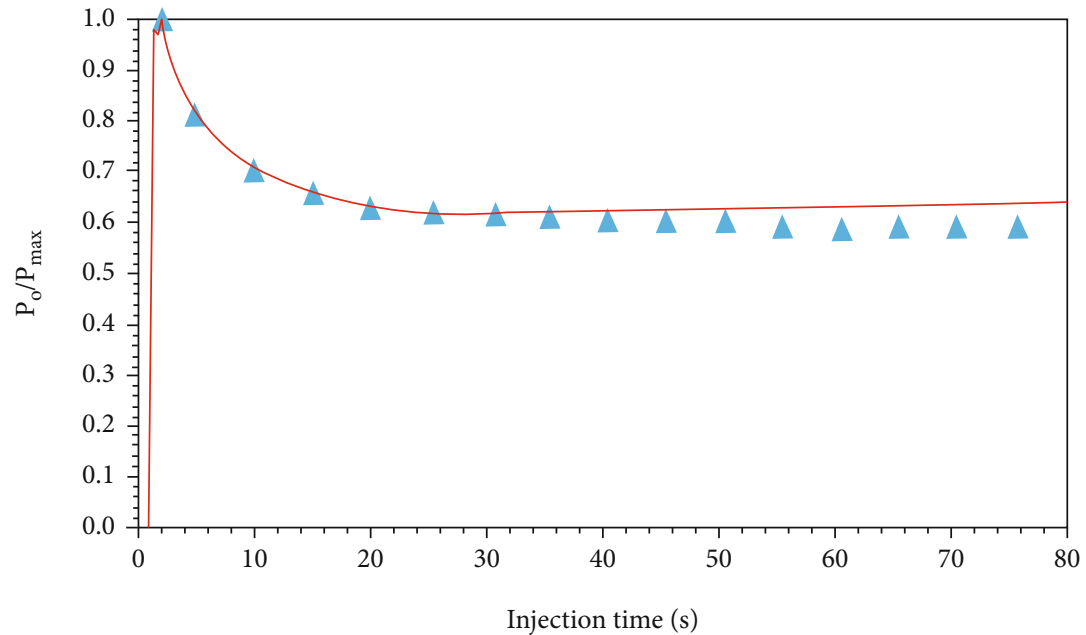

$\triangle$ Analytical solution

_ Poroelaticity

FIgURE 2: Comparison of calculated dimensionless injection pressure with analytical model.

the tensile stress is positive and the compressive stress is negative [22]:

$$
\tau=c-\sigma \tan \phi
$$

According to the geometry of the mole circle, shear stress $\tau$ and normal stress $\sigma$ can be expressed as follows [34]:

$$
\left\{\begin{array}{l}
\tau=\frac{\sigma_{1}-\sigma_{3}}{2} \cos \phi, \\
\sigma=\frac{\sigma_{1}+\sigma_{3}}{2}+\frac{\sigma_{1}-\sigma_{3}}{2} \sin \phi,
\end{array}\right.
$$

where $\tau$ is the shear stress, $\sigma$ is the normal stress, $\varphi$ is the friction degree, $\sigma_{1}$ and $\sigma_{3}$ are the maximum and minimum principal stresses, respectively, and $\sigma_{2}$ is the intermediate principal stress.

Substitute equation (17) into equation (16), we have

$$
\frac{\sigma_{1}-\sigma_{3}}{2} \cos \phi=c-\left[\frac{\sigma_{1}+\sigma_{3}}{2}+\frac{\sigma_{1}-\sigma_{3}}{2} \sin \phi\right] \tan \phi
$$

Principal stress and principal deviatoric stress satisfy the following equation [32]:

$$
\left\{\begin{array}{l}
\sigma_{1}=\frac{2}{\sqrt{3}} \sqrt{J_{2}} \cos \Theta+\frac{1}{3} I_{1}, \\
\sigma_{2}=\frac{2}{\sqrt{3}} \sqrt{J_{2}} \cos \left(\frac{2 \pi}{3}-\Theta\right)+\frac{1}{3} I_{1}, \\
\sigma_{3}=\frac{2}{\sqrt{3}} \sqrt{J_{2}} \cos \left(\frac{2 \pi}{3}+\Theta\right)+\frac{1}{3} I_{1},
\end{array}\right.
$$

where $\sigma_{1}$ and $\sigma_{3}$ are the maximum and minimum principal stresses, respectively, $\sigma_{2}$ is the intermediate principal

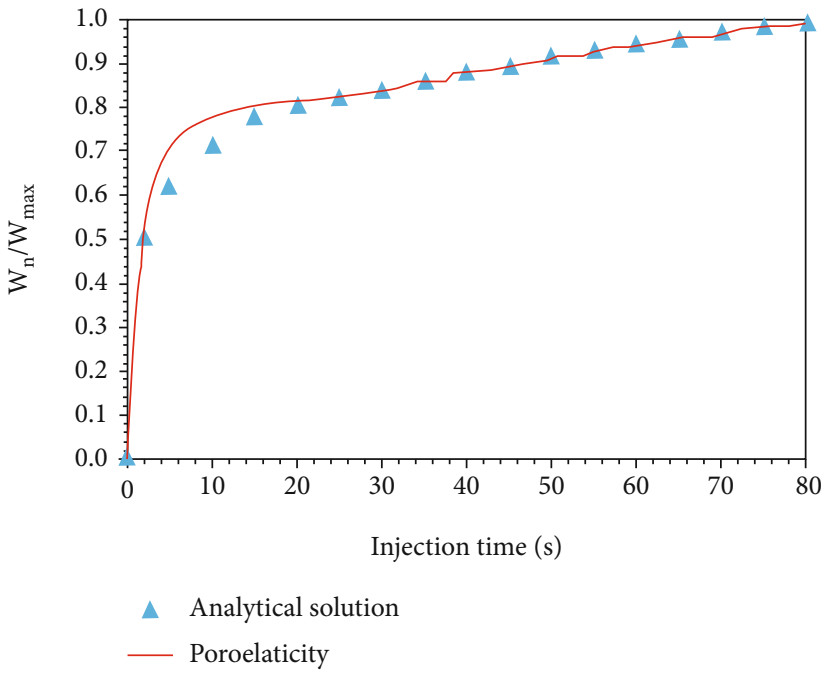

FIgURE 3: Comparison of calculated dimensionless wellbore fracture width with analytical model.

stress, $I_{1}$ is the first invariant of stress tensor, $J_{2}$ is the second invariant of deviatoric stress, and $\Theta$ is the deviatoric polar angle.

Substitute equation (19) into equation (18):

$$
\begin{aligned}
F= & \frac{1}{3} I_{1} \sin \phi+\sqrt{J_{2}} \sin \left(\Theta+\frac{\pi}{3}\right) \\
& +\frac{\sqrt{J_{2}}}{\sqrt{3}} \cos \left(\Theta+\frac{\pi}{3}\right) \sin \phi-c \cos \phi=0 .
\end{aligned}
$$

Equivalent compressive stress $p$, Mises equivalent stress $q$, the first invariant of stress tensor $I_{1}$, and the 

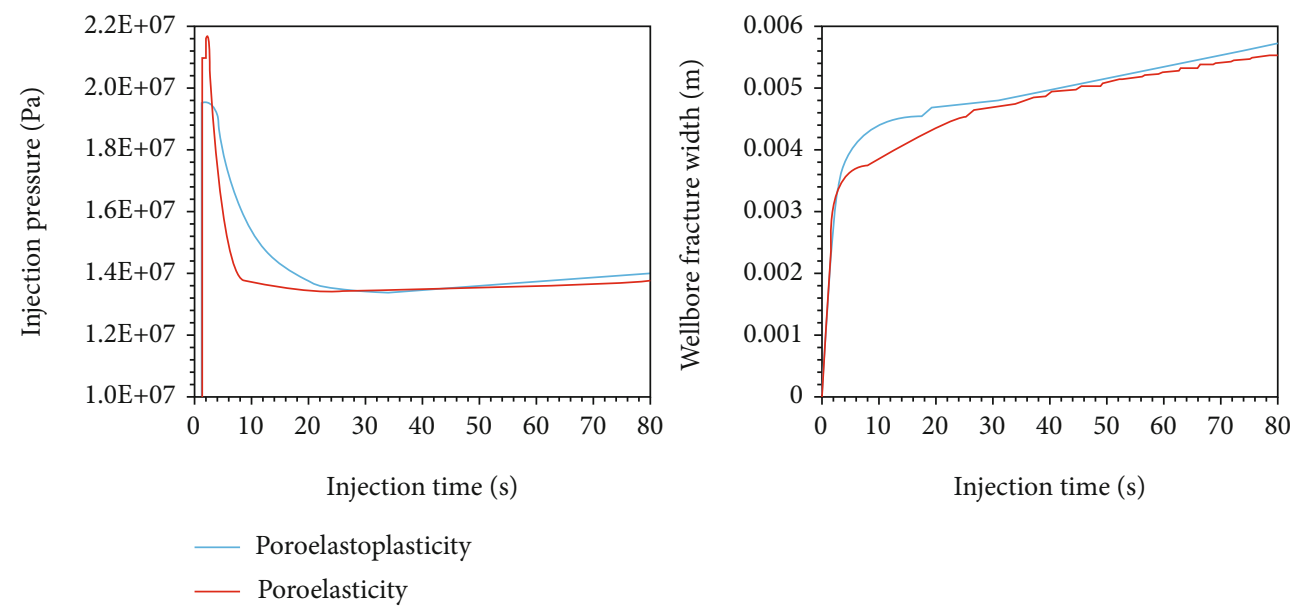

FIGURE 4: Comparison of injection pressure and wellbore fracture width calculated by poroelastic and poroelastoplastic models.

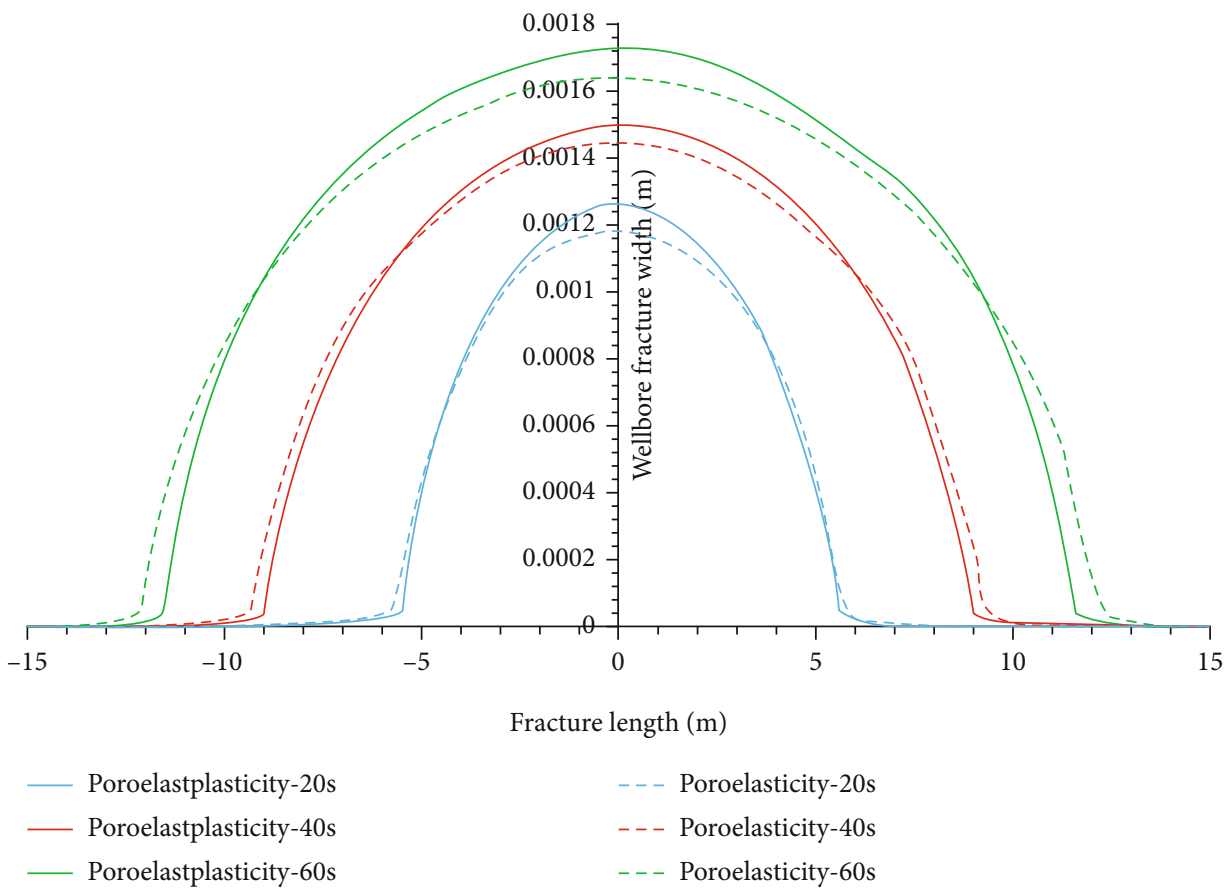

FIGURE 5: Comparison of fracture parameters with different time calculated in poroelastic and poroelastoplastic formation.

second invariant of deviatoric stress $J_{2}$ satisfy the following equation [25]:

$$
\left\{\begin{array}{l}
p=-\frac{1}{3} \operatorname{trace}(\sigma)==-\frac{I_{1}}{3}, \\
q=\sqrt{\frac{3}{2} s_{i j} s_{i j}}=\sqrt{3 J_{2}}, \\
\cos (3 \Theta)=\frac{r^{3}}{q^{3}},
\end{array}\right.
$$

where $p$ is the equivalent pressure stress, $q$ is the Mises equivalent stress, $r$ is the third invariant of deviatoric stress, and $s$ is the deviatoric stress.
Substitute equation (21) into equation (20):

$$
F=f(p, q, \Theta)=R_{m c} q-p \tan \phi-c=0,
$$

where

$$
R_{m c}=\frac{1}{\sqrt{3} \cos \phi} \sin \left(\Theta+\frac{\pi}{3}\right)+\frac{1}{3} \cos \left(\Theta+\frac{\pi}{3}\right) \tan \phi .
$$

In the case of equation (23), there will be sharp angles on the yield surface, leading to not unique plastic flow direction, which leads to tedious calculation and slow convergence. In order to solve this problem, Menetrey and Willam [35] 
PEE

(Avg: 75\%)

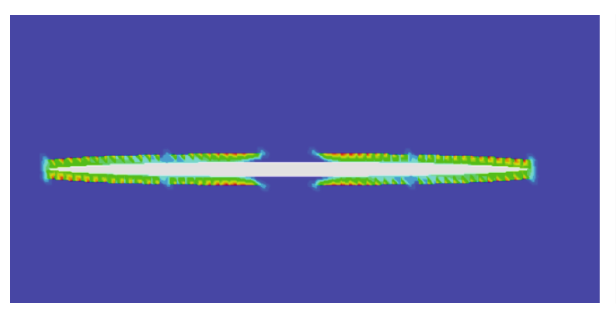

(a) Injection time at $20 \mathrm{~s}$

PEE

(Avg: $75 \%$ )

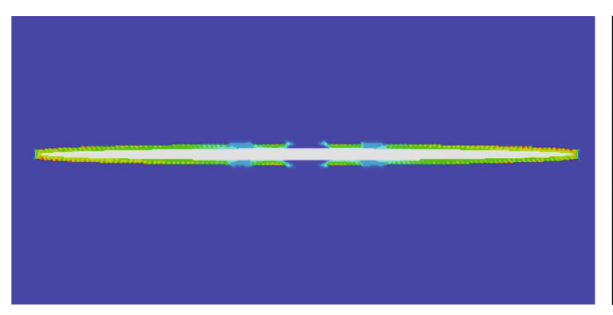

(c) Injection time at $60 \mathrm{~s}$

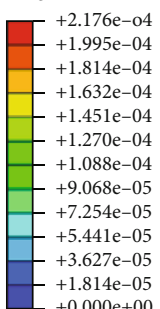

$+0.000 \mathrm{e}+00$

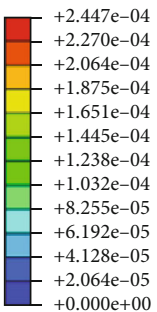

$+2.064 \mathrm{e}-05$
$+0.000 \mathrm{e}+00$

FIGURE 6: Equivalent plastic strain zone of fracture varies with injection time.
PEER

(Avg: $75 \%$ )

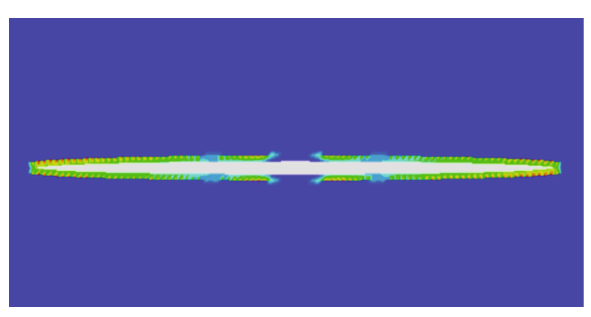

(b) Injection time at $40 \mathrm{~s}$

(Avg: 75\%)

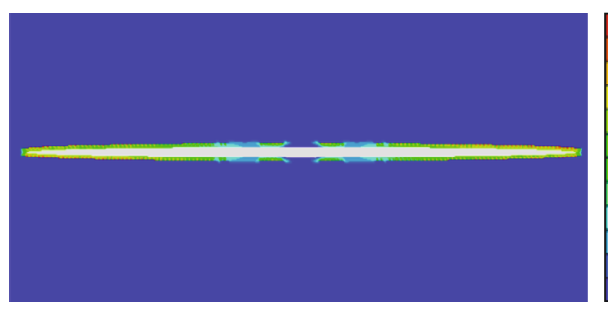

$+1.913 \mathrm{e}-04$

- $+1.488 \mathrm{e}-04$

(d) Injection time at $80 \mathrm{~s}$
$+2.550 \mathrm{e}-04$

$+2.338 \mathrm{e}-04$

$+2.125 \mathrm{e}-04$

$+1.700 \mathrm{e}-04$

$+1.275 \mathrm{e}-04$

$+1.275 \mathrm{e}-04$
$+1.063 \mathrm{e}-04$

$+1.063 \mathrm{e}-04$
$+8.500 \mathrm{e}-05$

$+8.500 \mathrm{e}-05$
$+6.375 \mathrm{e}-05$

$+6.375 \mathrm{e}-05$
$+4.250 \mathrm{e}-05$

$+4.250 \mathrm{e}-05$
$+2.125 \mathrm{e}-05$

$+0.000 \mathrm{e}+00$

$+2.407 \mathrm{e}-04$ 

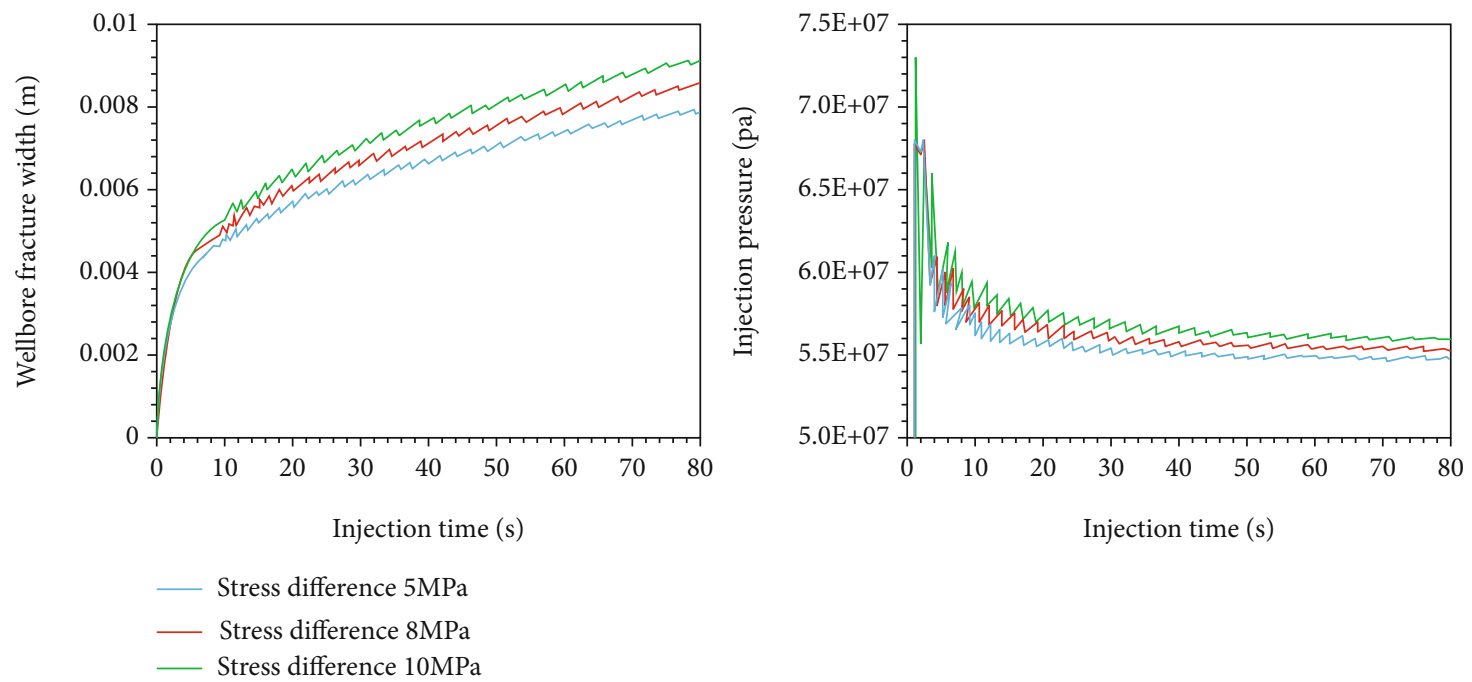

FIGURE 8: Effect of stress difference on wellbore fracture width and injection pressure.

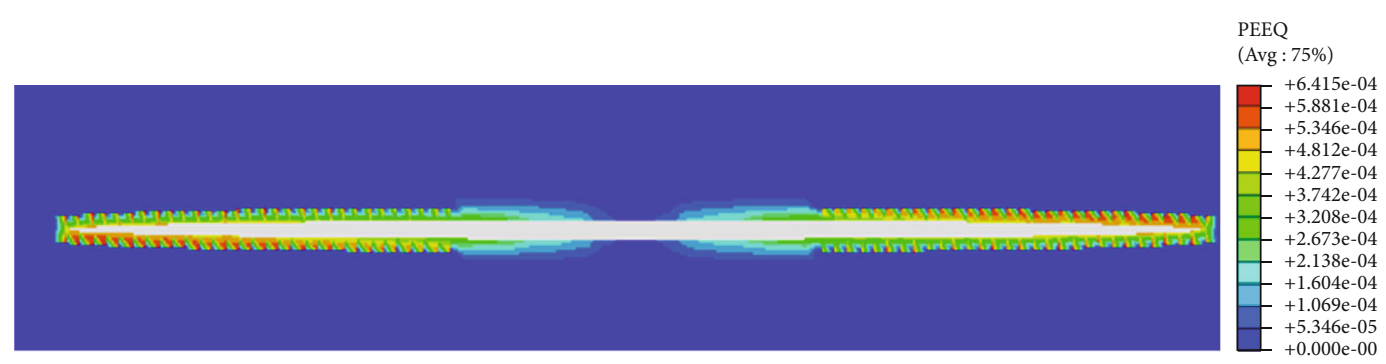

(a) Stress difference $5 \mathrm{MPa}$

PEEQ (Avg: $75 \%)$

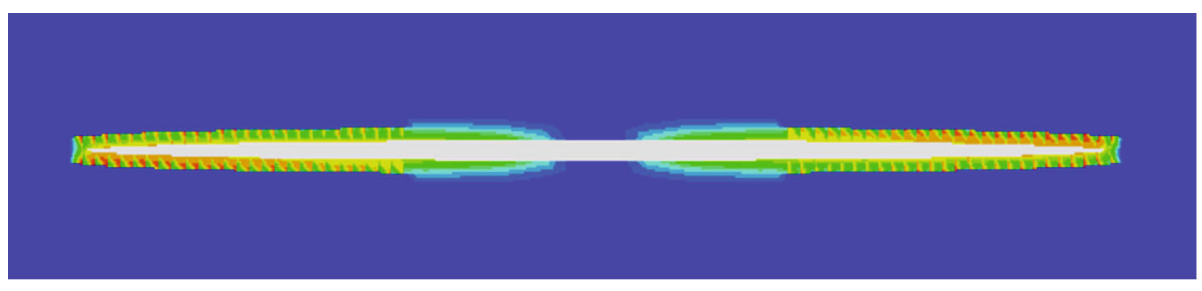

$+1.438 \mathrm{e}-03$

$+1.319 \mathrm{e}-03$

$+1.199 \mathrm{e}-03$

$+1.079 \mathrm{e}-03$

$+9.590 \mathrm{e}-04$
$+8.391 \mathrm{e}-04$

$+8.391 \mathrm{e}-04$

+

$+5.994 \mathrm{e}-04$
$+4.795 \mathrm{e}-04$

$+3.596 \mathrm{e}-04$

$+3.596 \mathrm{e}-04$

$+2.397 \mathrm{e}-04$

$+1.199 \mathrm{e}-04$

(b) Stress difference $8 \mathrm{MPa}$

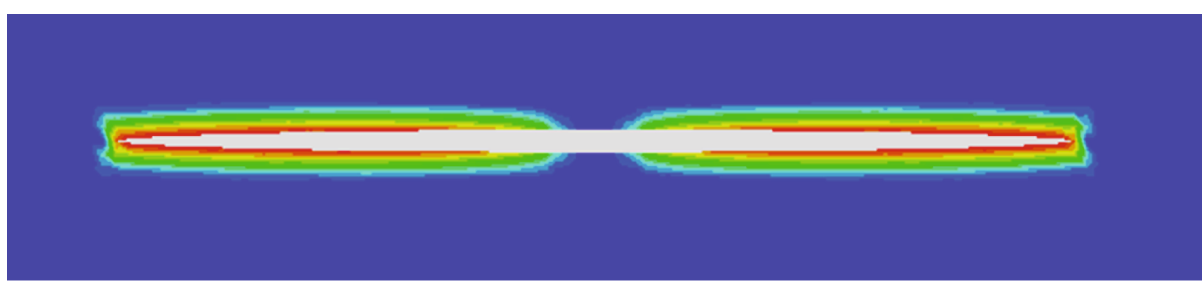

$\left[\begin{array}{l}+1.485 \mathrm{e}-03 \\ +1.361 \mathrm{e}-03\end{array}\right.$

$+1.361 \mathrm{e}-03$

$+1.238 \mathrm{e}-03$

$+1.114 \mathrm{e}-03$

(9.56

$+8.664 \mathrm{e}-04$
$+7.426 \mathrm{e}-04$

$+7.426 \mathrm{e}-04$

$+6.188 \mathrm{e}-04$

$+4.951 \mathrm{e}-04$

$+3.713 \mathrm{e}-04$

$+2.475 \mathrm{e}-04$

(c) Stress difference $10 \mathrm{MPa}$

FIgURE 9: Effect of stress difference on equivalent plastic strain zone of fracture. 


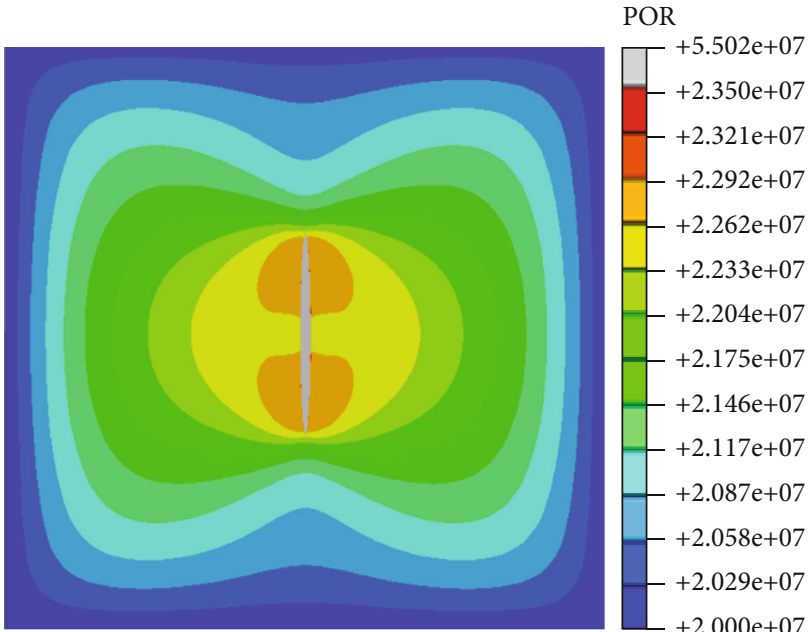

(a) Stress difference $5 \mathrm{MPa}$

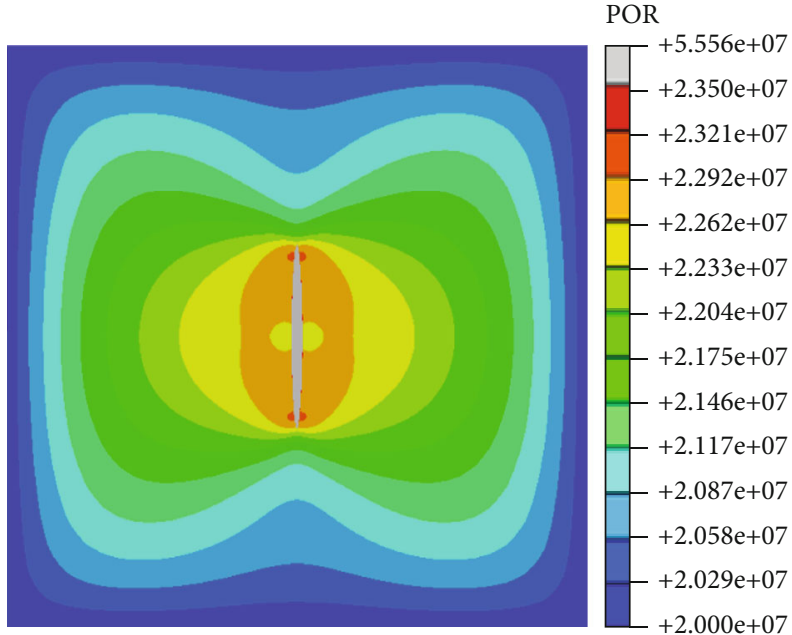

(b) Stress difference $8 \mathrm{MPa}$

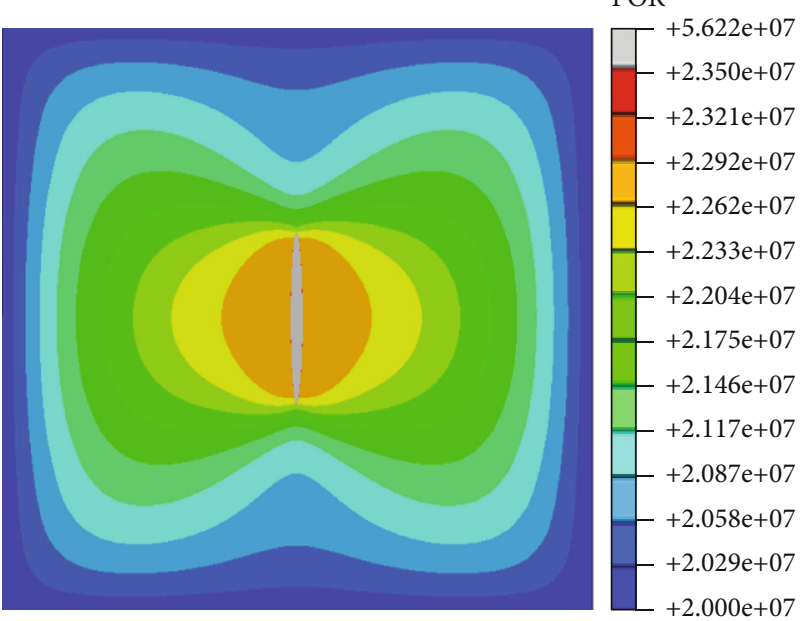

(c) Stress difference $10 \mathrm{MPa}$

FigURE 10: Effect of stress difference on pore pressure.

proposed a continuous smooth elliptic function as a plastic potential surface.

$$
G=\sqrt{\left(\varepsilon c_{0} \tan \psi\right)^{2}+\left(R_{m w} q\right)^{2}}-p \tan \psi
$$

where

$$
\begin{aligned}
R_{m w}= & \frac{4\left(1-e^{2}\right) \cos ^{2} \Theta+(2 e-1)^{2}}{2\left(1-e^{2}\right) \cos \Theta+(2 e-1) \sqrt{4\left(1-e^{2}\right) \cos ^{2} \Theta+5 e^{2}-4 e}} \\
& \cdot \frac{3-\sin \phi}{6 \cos \phi},
\end{aligned}
$$

$$
e=\frac{3-\sin \phi}{3+\sin \phi},
$$

where $\psi$ is the dilation angle measured in the $p-R_{m w} q$ plane at high confining pressure and can depend on temperature and predefined field variables; $c_{0}$ is the initial cohesion yield stress; $\varepsilon$ is the eccentricity ratio, and here is assumed to be $0.1 ; e$ is the "out of roundedness" of the deviatoric section in terms of the ratio between the shear stress along the extension meridian and the shear stress along the compression meridional.

2.4. Fluid Flow in Fracture and Formation. Once the fracture is formed, fluid will flow into the fracture at once. Fluid flow in the fracture follows the mass conservation law [36]:

$$
\frac{\partial w}{\partial t}+\frac{\partial q_{t}}{\partial s}+v_{t}+v_{b}=0
$$

where $q_{t}$ is the injection flow rate, $w$ is the fracture width, $s$ is the fracture length, $t$ is injection time, and $v_{t}$ and $v_{b}$ are the fracturing fluid leakoff rate through the top and bottom fracture surfaces, respectively. 


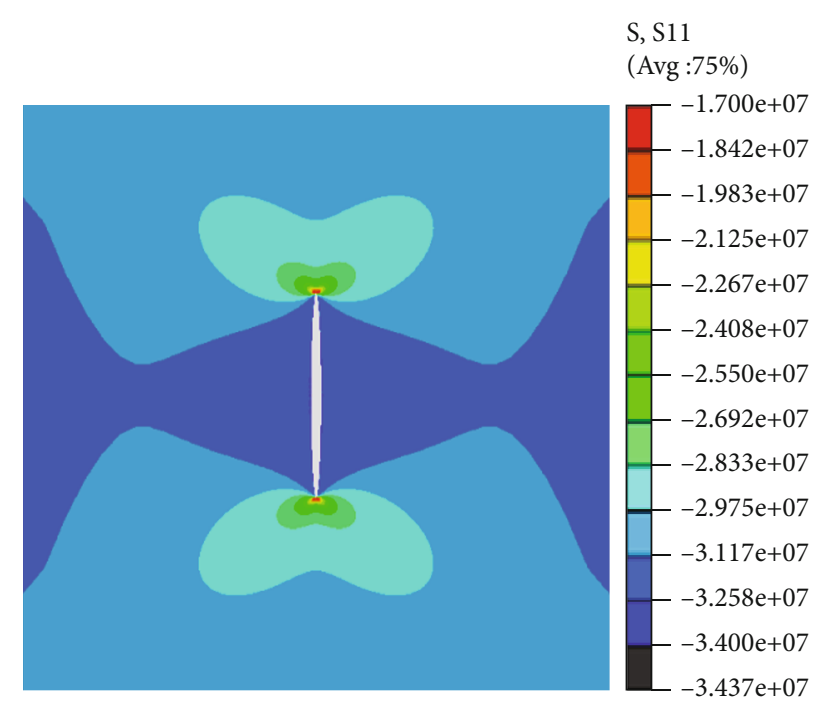

(a) Stress difference $5 \mathrm{MPa}$
S, S11

(Avg :75\%)
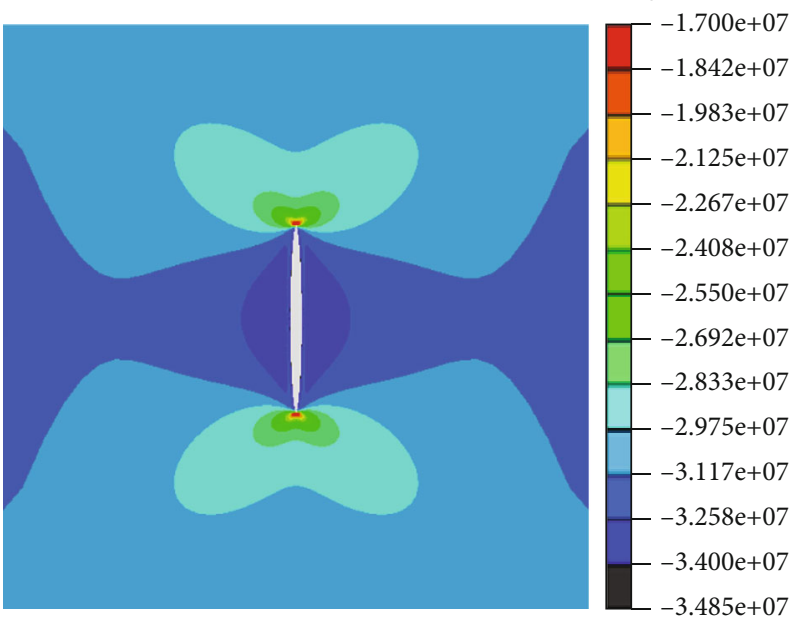

(b) Stress difference $8 \mathrm{MPa}$

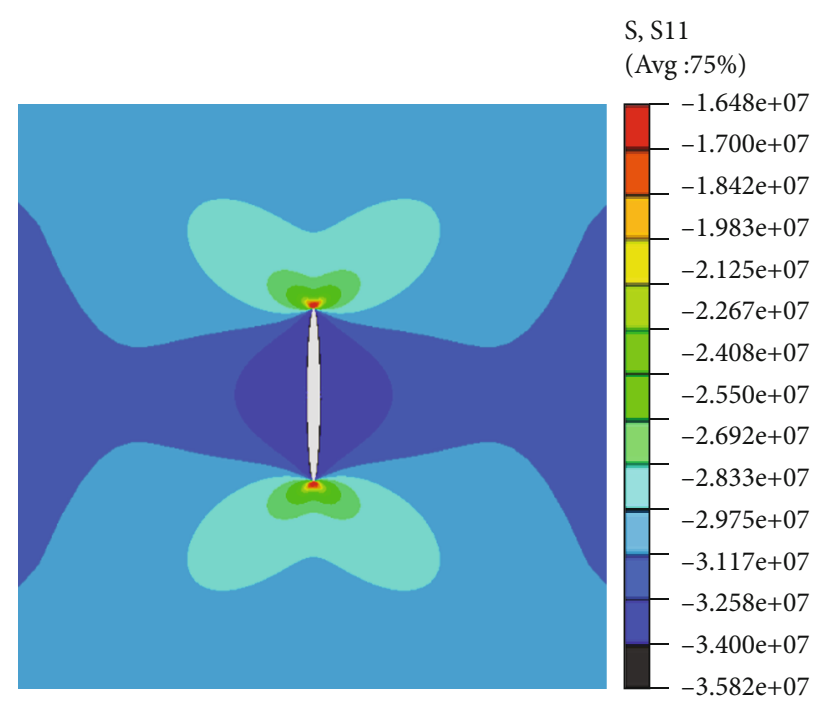

(c) Stress difference $10 \mathrm{MPa}$

FiguRE 11: Effect of stress difference on stress on $x$ direction.

Both tangential flow along and normal flow across the fracture surfaces can be calculated using the Poiseuille equation $[37,38]$ :

$$
q_{t}=\frac{w^{3}}{12 \mu} \frac{\partial p}{\partial s}
$$

where $\mu$ is the fluid viscosity and $p$ is the fluid pressure.

Fluid leakoff rate is mainly affected by pressure and leakoff coefficient, which satisfy the following equation [39, 40]:

$$
\left\{\begin{array}{l}
v_{t}=c_{t}\left(p-p_{\text {top }}\right), \\
v_{b}=c_{t}\left(p-p_{\text {bot }}\right),
\end{array}\right.
$$

where $c_{t}$ is the fluid leakoff coefficients and $p_{\text {top }}$ and $p_{\text {bot }}$ are the pressure in the top and bottom fracture surface, respectively.
When the fluid leaks off from the fracture, it will flow through the formation in accordance with the Darcy law. The mass conservation equation is expressed as [34]:

$$
\nabla\left(\frac{\rho_{w} k_{w}}{b_{w} \mu_{w}} \nabla p_{w}\right)+q_{w}=\frac{\partial}{\partial t}\left(\frac{\varphi \rho_{w} s_{w}}{b_{w}}\right)
$$

where $\rho_{w}$ is the water permeability, $k_{w}$ is the water permeability, $p_{w}$ is water pressure in formation, $b_{w}$ is the water compression coefficient, $\mu_{w}$ is the water viscosity, $q_{w}$ is the leakoff fluid, $S_{w}$ is the water saturation, and $\phi$ is the effective porosity.

2.5. Cohesive Crack Model. The singularity of the fracture tip stress field will affect the convergence of the calculation results. In order to solve this problem, CZM is adopted to simulate the initiation and propatation of fractures. This method is implemented by embedding an artificially 


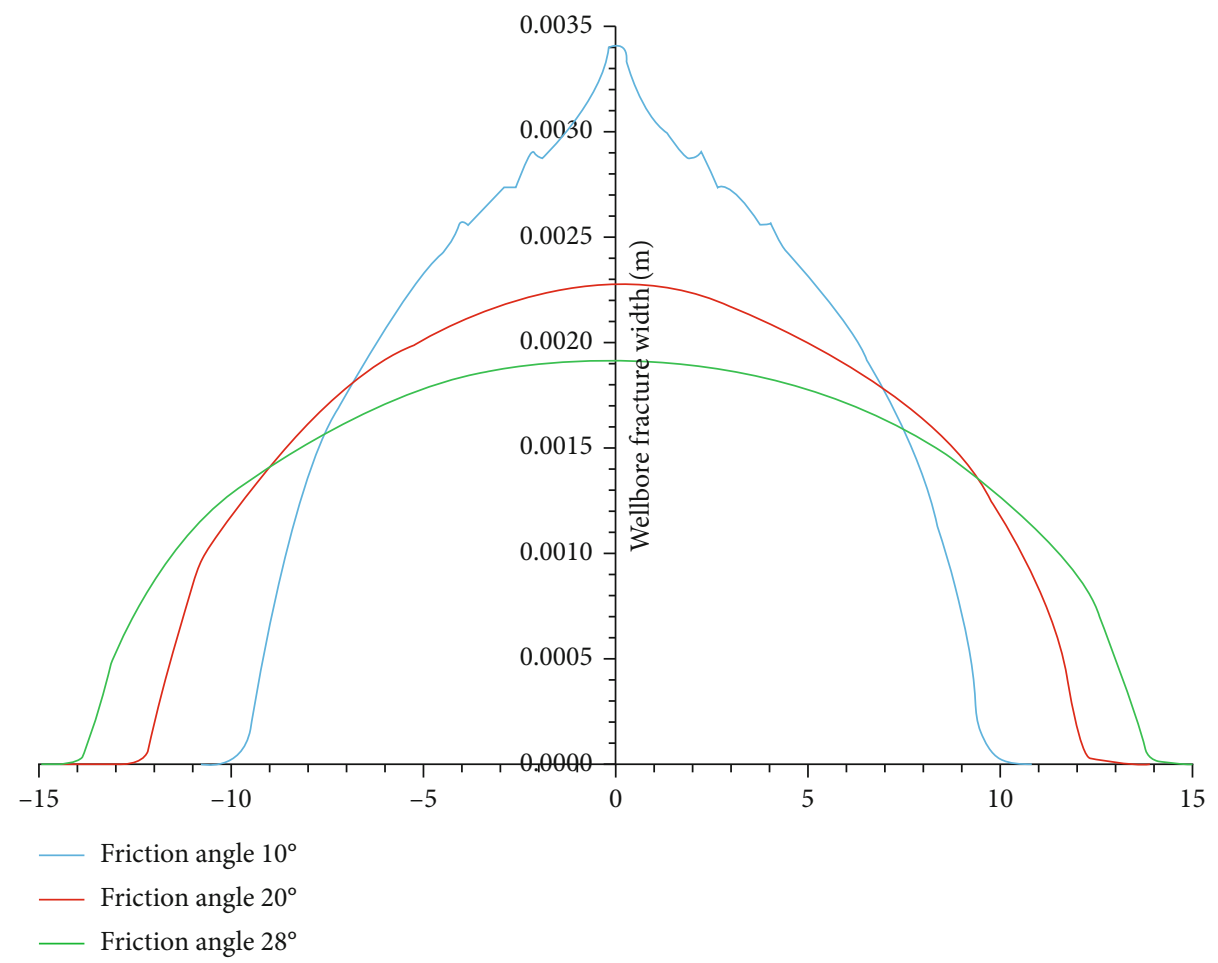

FIGURE 12: Effect of stress difference on fracture width and length.
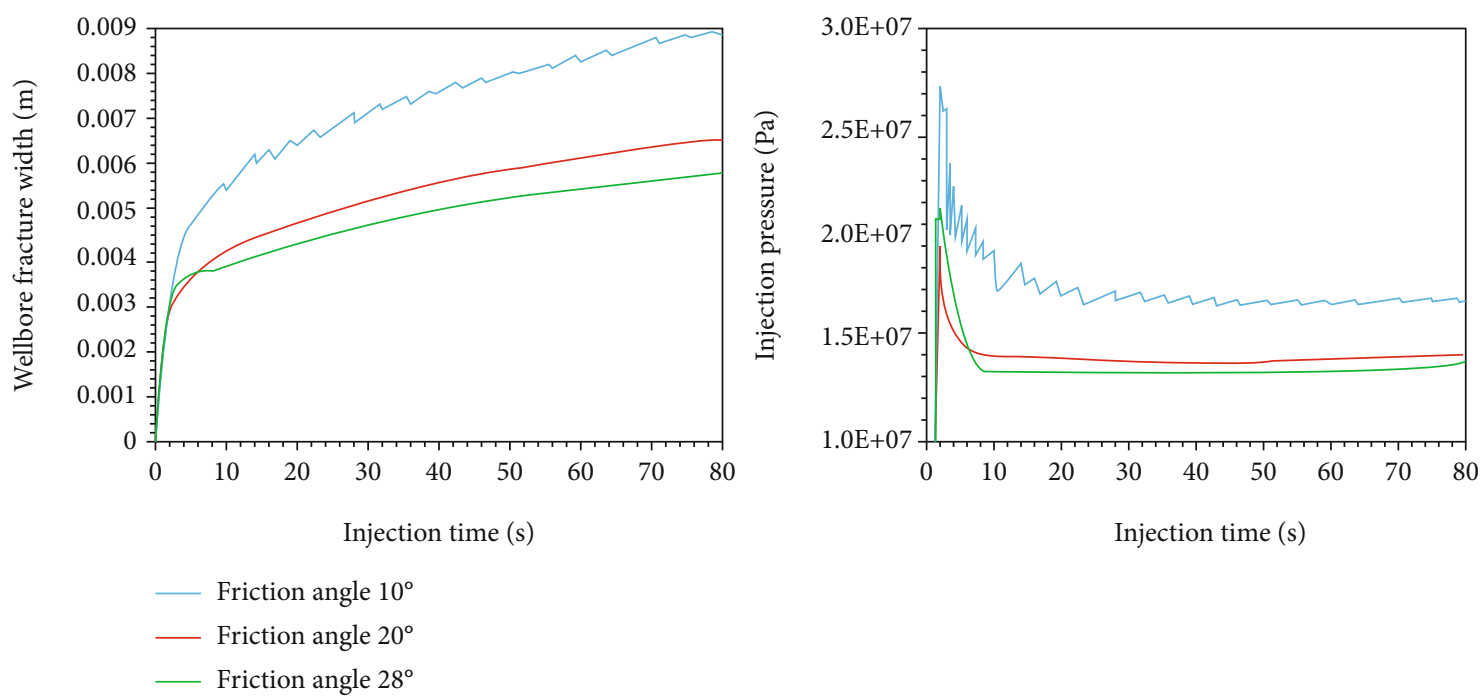

FIGURE 13: Effect of stress difference on wellbore fracture width and injection pressure.

predefined path of cohesive element into the formation. The cohesive element glues two conjugated cohesive surfaces of the reservoir pressure/displacement element. The failure of these element obeys the traction/separation law in the vertical or shear direction $[41,42]$. When the cohesive element is completely destroyed, the two bound cohesive surfaces are separated, and hydraulic fracture is generated. When the maximum nominal stress criterion is adopted for rock failure, initiation propagation occurs as the maximum nominal stress ratio reaches a critical value [43-45]:

$$
\begin{aligned}
& f_{c}=\max \left\{\frac{\left\langle T_{n}\right\rangle}{T_{n}^{0}}, \frac{T_{s}}{T_{s}^{0}}\right\}, \\
& 1 \leq f_{c} \leq 1+f_{t},
\end{aligned}
$$

where $\delta_{n}$ and $\delta_{s}$ are, respectively, the normal and tangential displacement jump vector, $\delta_{\text {eq }}$ are effective displacement, 


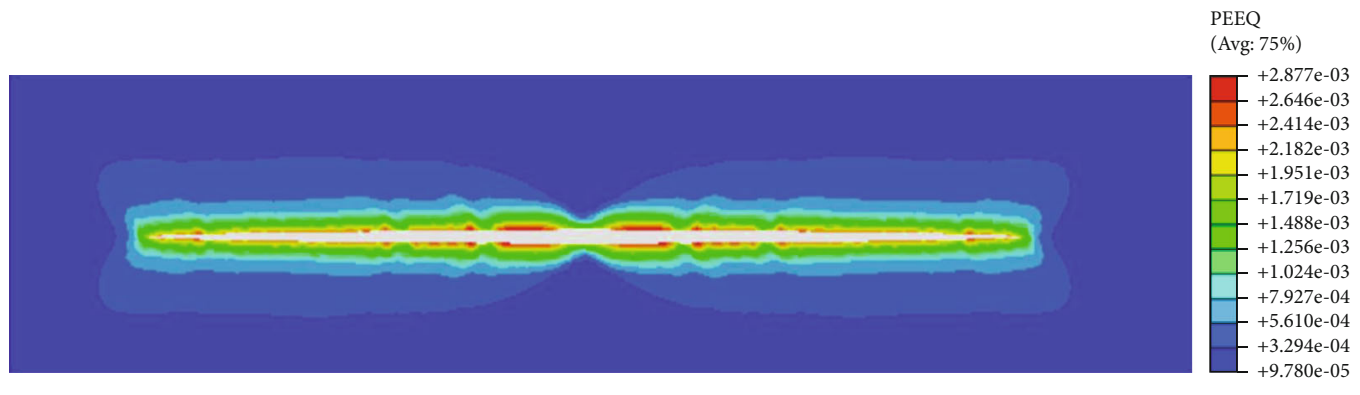

(a) Friction angle $10^{\circ}$

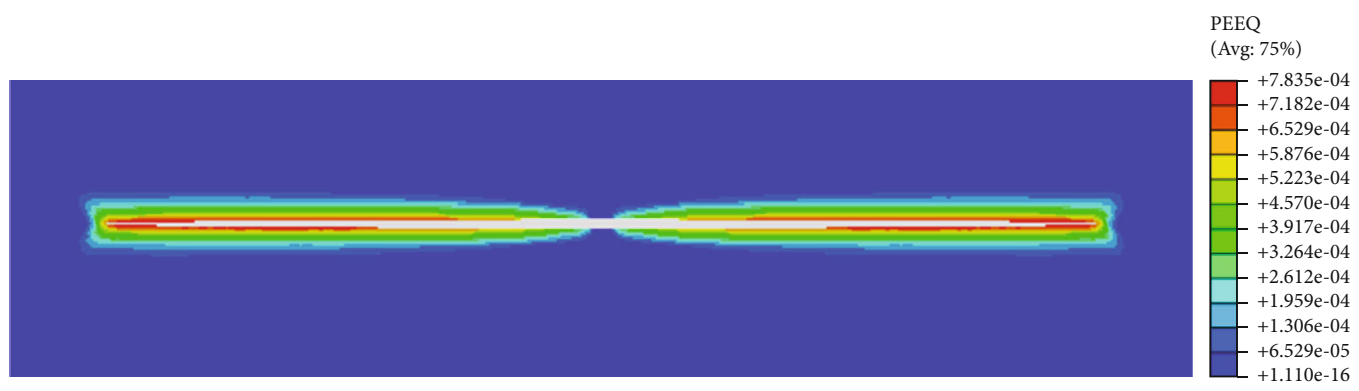

(b) Friction angle $20^{\circ}$

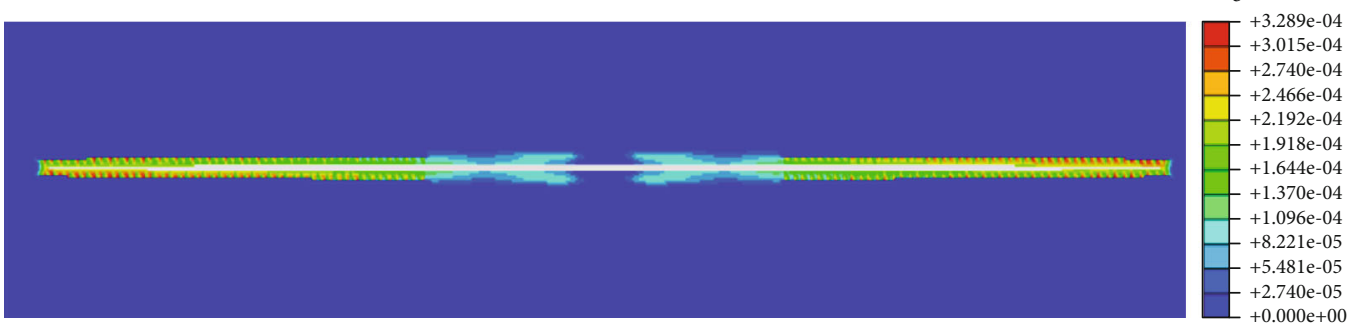

(c) Friction angle 28

FIGURE 14: Effect of friction angle on equivalent plastic strain zone of fracture.

$T_{n}^{0}$ and $T_{s}^{0}$ are, respectively, the normal and tangential stress component of the stress element under a linear elastic condition, $\left\langle>\right.$ denotes the Macaulay bracket, $f_{c}$ is a parameter evaluating the fracture failure, and $f_{t}$ is assured to be 0.05 .

The fracture damage evolution is determined by damage variables, and the expressions of damage effects on the normal and tangential stress components of the element can be obtained as [44-46]

$$
\begin{aligned}
& T_{n}= \begin{cases}(1-d) T_{n}^{0}, & T_{n}^{0} \geq 0 \\
T_{n}^{0}, & T_{n}^{0}<0\end{cases} \\
& T_{s}=(1-d) T_{s}^{0},
\end{aligned}
$$

where $d$ is the scalar damage variable between fractures, 0 $<d<1$, and $T_{n}$ and $T_{s}$ are, respectively, the values of the normal stress component and the tangential stress component of the traction/separation model.

When the critical fracture energy of rock material along the first and second shear directions is similar, the damage evolution during fracture propagation can also be deter- mined by the Benzeggagh-Kenane fracture criterion [47]. The combined energy dissipated by failure $G_{c}$ is defined as

$$
G^{c}=G_{\mathrm{I}}^{c}+\left(G_{\mathrm{II}}^{c}-G_{\mathrm{I}}^{c}\right)\left(G_{\mathrm{II}}^{c}-G_{\mathrm{I}}^{c}\right)^{\eta}
$$

where $G_{c}$ is the critical fracture energy release rate, $G c I$ and $G c I I$ are the normal and first shear direction fracture toughness values, $G_{\text {I }}$ and $G_{\text {II }}$ are the normal and shear direction fracture energy release rate, and $\eta$ is a material properties parameter; here is assumed to be 2.3.

2.6. Model Solution. The iterative coupling approach is used to solve the coupled model. Fluid flow and solid deformation are solved separately and sequentially, and the coupling terms are iterated until convergence. The fluid flow model is solved first based on the initial guess of injection pressure; then, the solid deformation is solved by the XFEM stiffness matrix, which is based on the solution of the previous iteration. The pressure distribution is calculated until convergence is reached. If the convergence criterion is not satisfied, the guessing value is modified as $p_{n+1}=\omega p_{n-1}+(1-\omega) p_{n}$; the pressure distribution and 


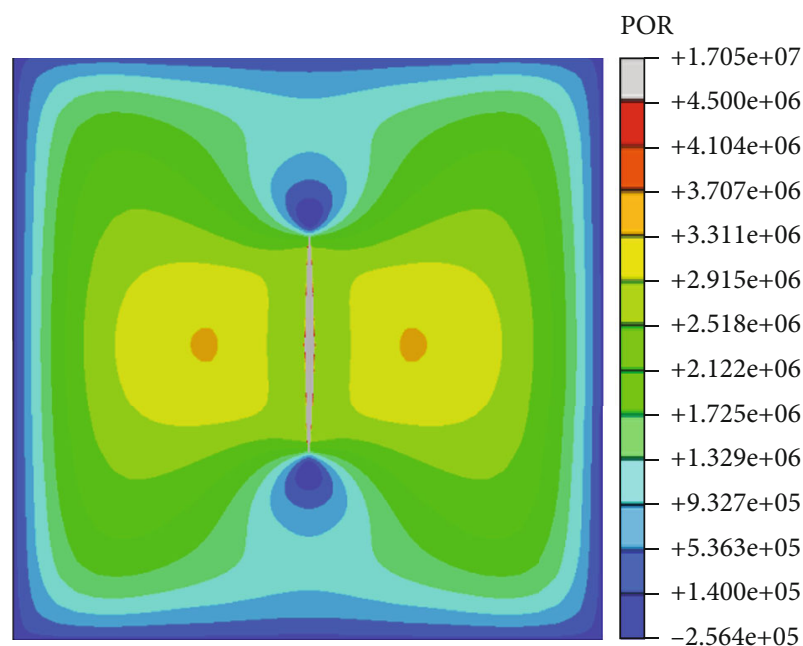

(a) Friction angle $10^{\circ}$

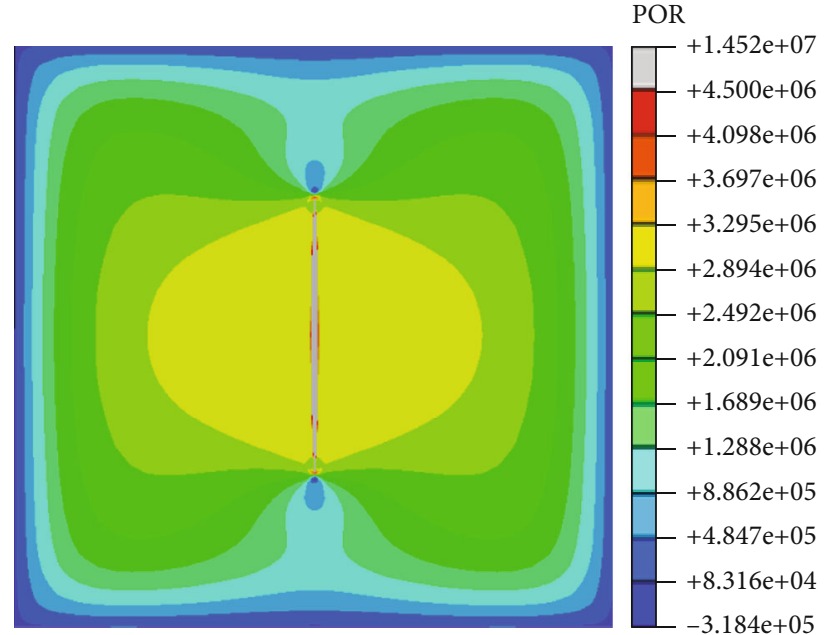

(b) Friction angle $20^{\circ}$

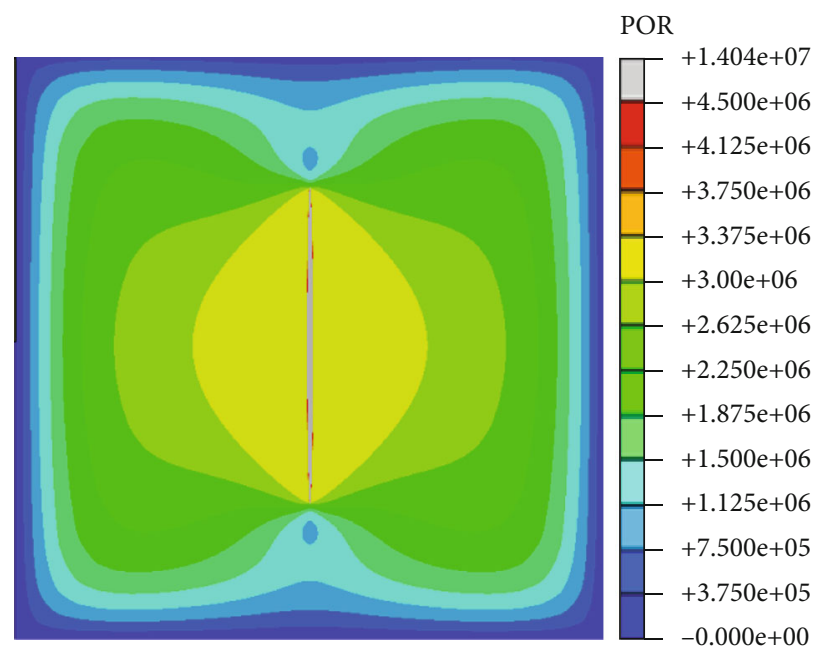

(c) Friction angle $28^{\circ}$

FIGURE 15: Effect of friction angle on pore pressure.

rock deformation will be recalculated with the modified value. When the rock failure condition is met, the fracture will propagate and add a new element for the next time step.

\section{Model Verification}

In order to simulate $\mathrm{HF}$ in elastic-plastic formation, the Abaqus 6.14 software has been utilized to solve this coupling model. The size of geological model is set as $50 \times 50 \mathrm{~m}$ with a cohesive element embedded in the central of the model. The injection point is in the center of the cohesive zone. The minimum principal stress is in $y$ direction. All the external boundary displacements are fixed in normal directions. The geological model is shown in Figure 1, and the input parameters of simulation model are presented in Table 1. The simulation process consists of two steps: geostatic step and HF step. The purpose of geostatic step is to balance the initial formation stress and fluid pressure. HF step is to simulate the change of fluid injection, rock deformation, and fracture initiation and expansion during fracturing.

To verify the accuracy of the model, we compared the calculated results with KGD model. KGD model is a simple analytical model. The wellbore fracture width $\left(w_{o}\right)$ and injection pressure solution $\left(p_{w}\right)$ of KGD model can be given [48]:

$$
\begin{aligned}
& w_{o}=2.36\left[\frac{q^{3} \mu\left(1-v^{2}\right)}{E h^{3}}\right]^{1 / 6} t^{1 / 3}, \\
& p_{w}=1.09\left[\frac{\mu E^{2}}{\left(1-v^{2}\right)^{2}}\right]^{1 / 3} t^{-1 / 3}+\sigma_{\min } .
\end{aligned}
$$

We used the calculated dimensionless injection pressure (ratio of injection pressure to maximum injection pressure) and dimensionless wellbore fracture width (ratio of wellbore fracture width to maximum wellbore fracture width) to valid 


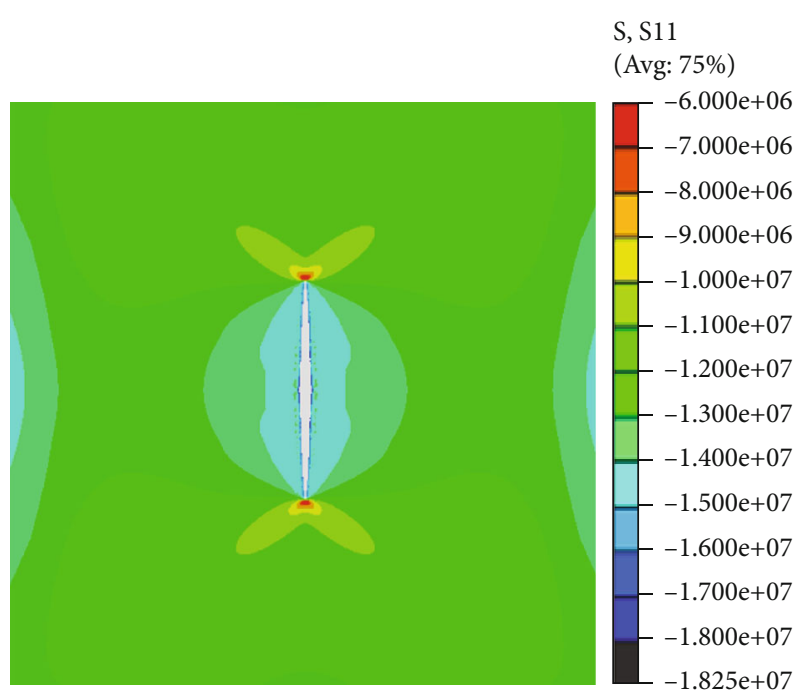

(a) Friction angle $10^{\circ}$

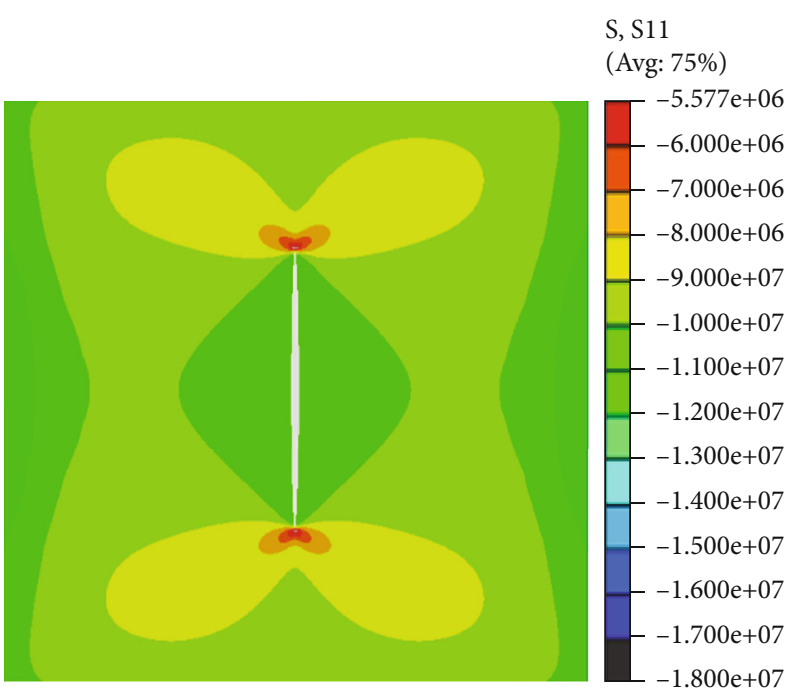

(b) Friction angle $20^{\circ}$

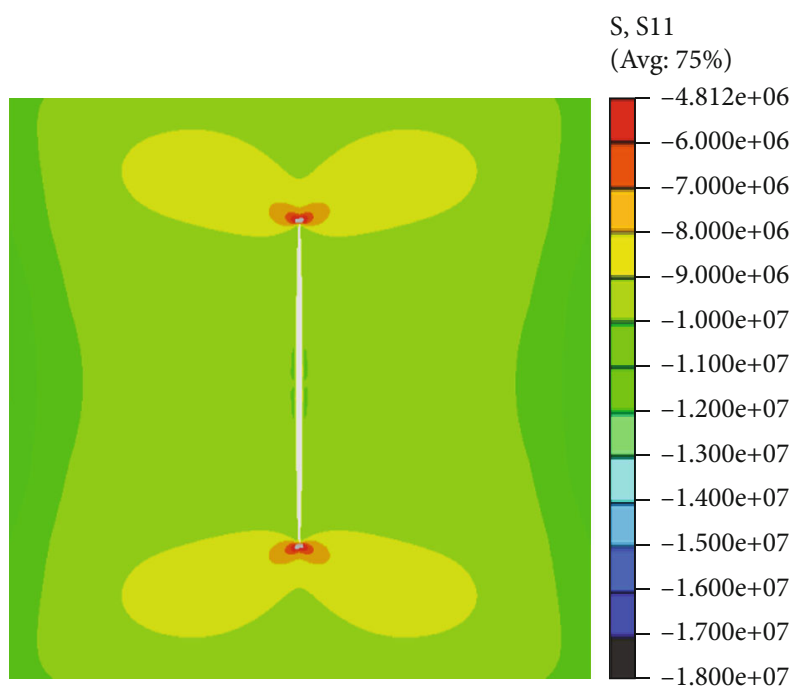

(c) Friction angle $28^{\circ}$

FIgURE 16: Effect of friction angle on stress on $x$ direction.

the model; the simulated results are presented in Figures 2 and 3. After the model is validated, the changes of injection pressure, fracture width, fracture length, and the equivalent plastic strain zone with time in elastic and elastic-plastic formation are also investigated by the model. The calculated results are demonstrated in Figures 4-6.

Figures 2 and 3 exhibit that the simulated dimensionless injection pressure and dimensionless wellbore fracture width are in good agreement with KGD model. The change trend of injection pressure and fracture width at the wellbore is also in accordance with KGD model. Injection pressure in both models is first increased and then decreased to a constant value. Wellbore fracture width is also gradually increasing with injection time. In early injection time, there is a slight deviation in between dimensionless wellbore fracture width calculated by our model and that calculated by KGD model.
This may be caused by fluid leakoff. On the whole, the agreement between the two models is encouraging.

Figure 4 shows that the injection pressure and fracture width at the wellbore in elastic-plastic formation are greater than that in elastic formation, and the breakdown pressure and propagation pressure are also greater in elastic-plastic formation. Injection pressure is first increased and then decreased to a constant value. Wellbore fracture width is also gradually increasing with injection time.

Figure 5 presents that fracture in elastic-plastic formation is incline to be wider and shorter than elastic formation. Because plastic damage requires more energy, plastic deformation of rock leads the fracture tip to be blunt, resulting fracture more difficult to extend. Figure 6 displays that the equivalent plastic strain area increases with injection time, and the largest plastic strain appears near the fracture tip. 


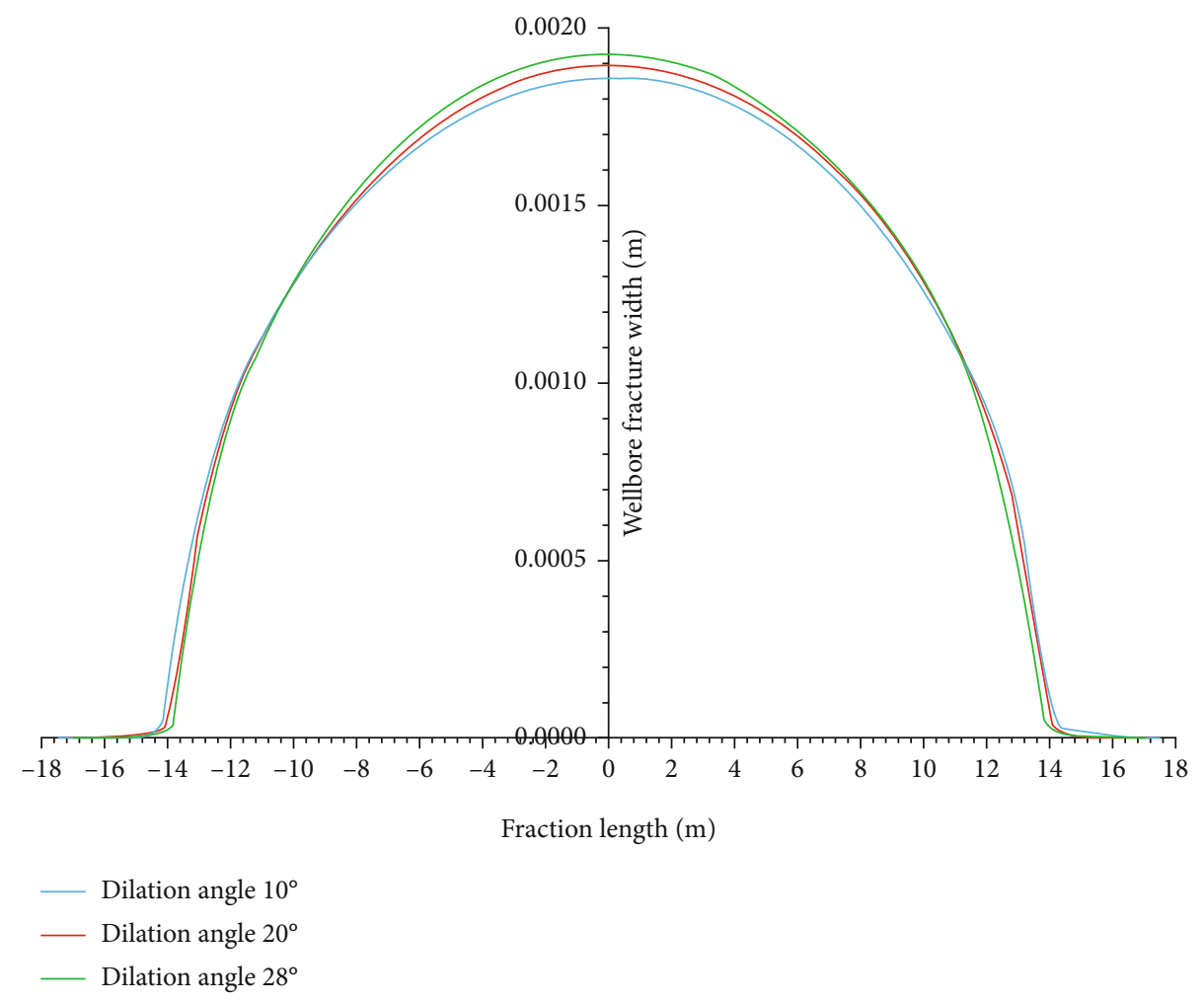

Figure 17: Effect of dilation angle on fracture width and length.
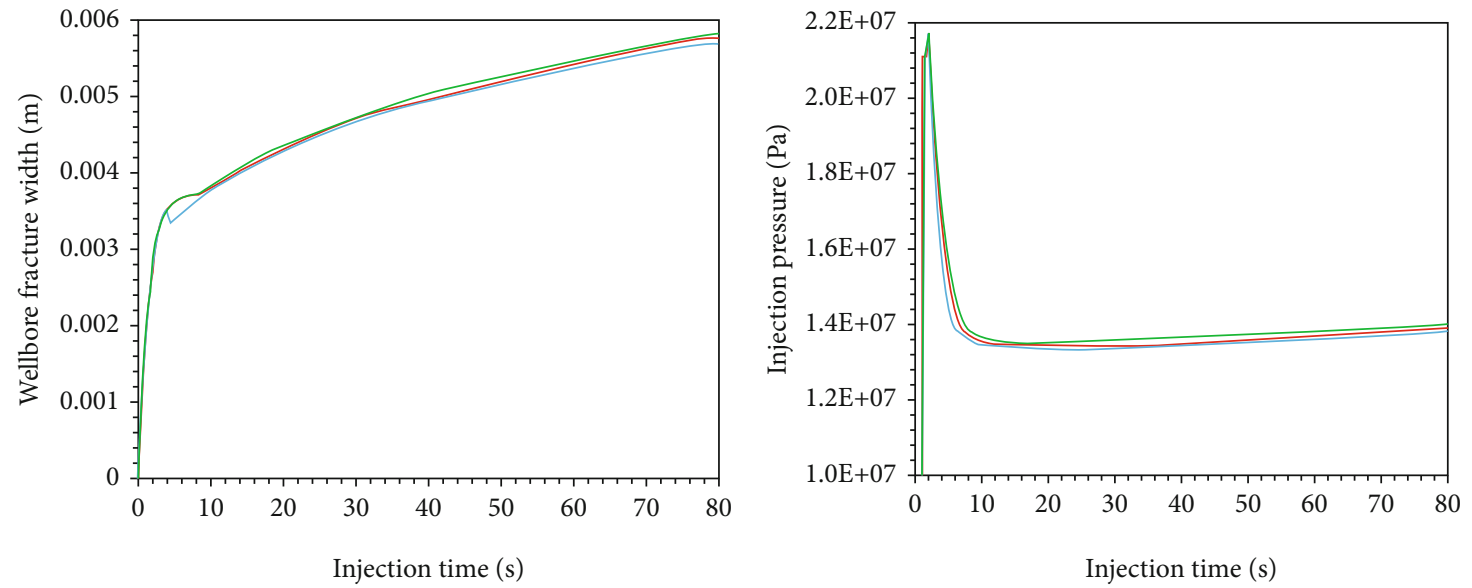

— Dilation angle $10^{\circ}$

- Dilation angle $20^{\circ}$

— Dilation angle $28^{\circ}$

FIGURE 18: Effect of dilation angle on wellbore fracture width and injection pressure.

The plastic deformation also causes rock compaction, which results that the porosity and permeability decrease around the fracture with less fluid leakoff and higher injection pressure.

\section{Numerical Results and Discussion}

4.1. Effect of Stress Difference on Fracture Propagation. The effects of horizontal principal stress differences on fracture width, length, injection pressure, fracture width at the wellbore, equivalent plastic strain of fracture, pore pressure, and induced stress are simulated. It is assumed that the minimum horizontal principal stress is constant at $30 \mathrm{MPa}$; the horizontal principal stress difference is $5 \mathrm{MPa}, 8 \mathrm{MPa}$, and $10 \mathrm{MPa}$, respectively; the pore pressure of the formation is $20 \mathrm{MPa}$; the injection time is $80 \mathrm{~s}$; and the friction angle and dilation angle of the rock are both $15^{\circ}$. The calculation results are presented in Figures 7-11. 


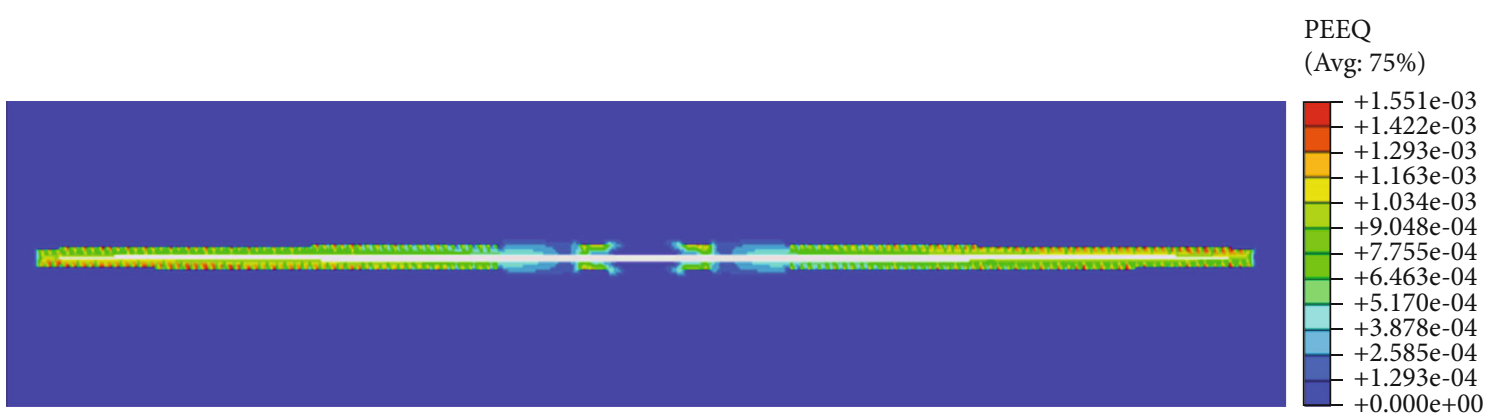

(a) Dilation angle $10^{\circ}$

PEEQ

(Avg: 75\%)

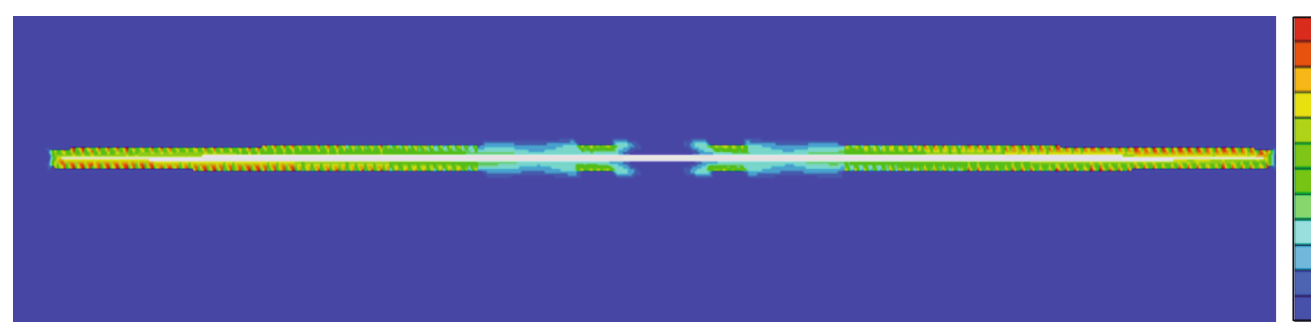

$+9.243 \mathrm{e}-04$

$+8.472 \mathrm{e}-04$

$+7.702 \mathrm{e}-04$

$+6.932 \mathrm{e}-04$

$+6.162 \mathrm{e}-04$

$+5.392 \mathrm{e}-04$

$+4.621 \mathrm{e}-04$

$+3.851 \mathrm{e}-04$

$+3.081 \mathrm{e}-04$

$+2.311 \mathrm{e}-04$

$+1.540 \mathrm{e}-04$

$+7.702 \mathrm{e}-05$

(b) Dilation angle $20^{\circ}$

$+0.000 \mathrm{e}+00$

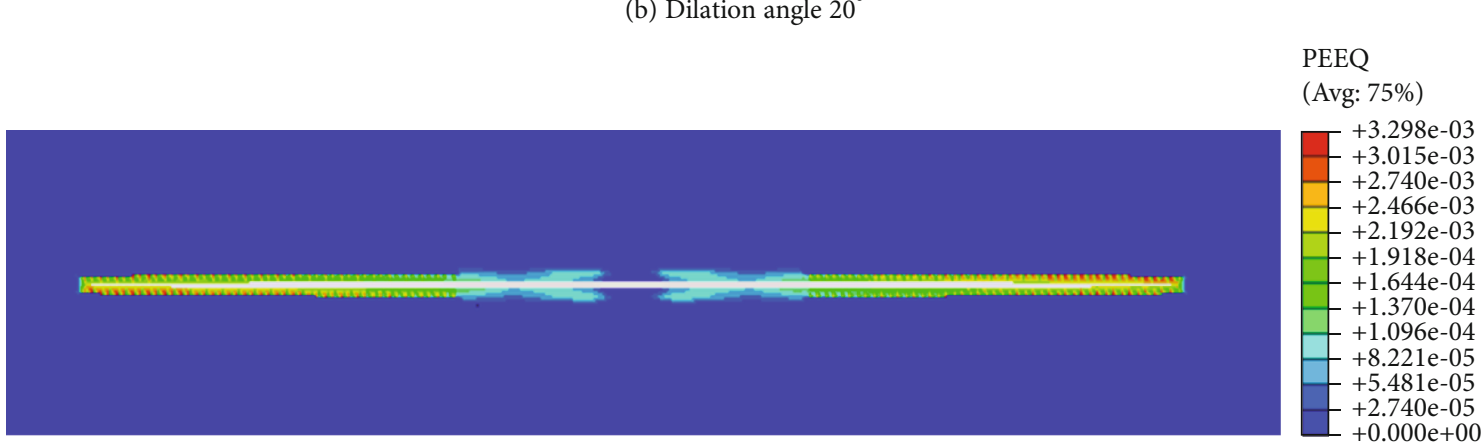

(c) Dilation angle $28^{\circ}$

Figure 19: Effect of dilation angle on equivalent plastic strain zone of fracture.

Figure 7 demonstrates that crack width increases and crack length decreases with the increasing stress difference. Figure 8 indicates that the crack width at the wellbore and injection pressure increases with the increase of horizontal stress difference. Figure 9 displays that the area of equivalent plastic strain around the crack also increases with the increase of horizontal stress difference. Figures 10 and 11 present that pore pressure and induced stress in $x$ direction surround the fracture also grows with the increasing stress difference. Because high stress difference is easy to generate large plastic zones, and rock compaction caused by the plastic deformation around the fracture leads to a decrease in porosity and permeability, which in turn makes it difficult for the fracturing fluid to flow into the formation, resulting greater pore pressure near the fracture surface. Meanwhile, the induced stress on the fracture surface also makes crack difficult to extent, because of the plastic effect. Therefore, plastic formations with high horizontal stress difference are benefit to form wide and short crack.
4.2. Effect of Friction Angle on Fracture Propagation. In order to study the influence of friction angle on hydraulic fracture propagation, the effects of friction angle on fracture width and length, injection pressure, fracture width at the wellbore, equivalent plastic strain, pore pressure, and induced stress are simulated. It is assumed that the minimum horizontal principal stress is constant at $10 \mathrm{MPa}$, the horizontal principal stress difference is $5 \mathrm{MPa}$, and the injection time is $80 \mathrm{~s}$. The friction angle of the rock is $10^{\circ}, 20^{\circ}$, and $28^{\circ}$, respectively, and dilation angle is equal to friction angle. The calculation results are presented in Figures 12-16.

Figure 12 demonstrates that crack width decreases with the increasing friction angle, while crack length increases with the increasing friction angle. Lower friction angle causes the fracture tip to be blunter. When friction angle is $10^{\circ}$, plastic deformation at the injection point has obviously appeared in the early stage of crack expansion, leading to a significant increase of crack width near the wellbore. Figure 13 indicates that the crack width at the wellbore and injection pressure 


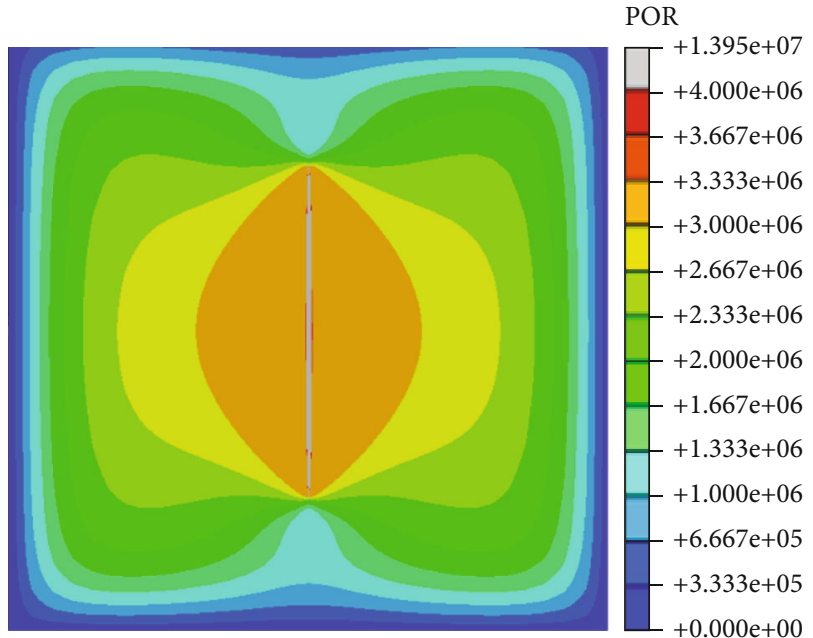

(a) Dilation angle $10^{\circ}$

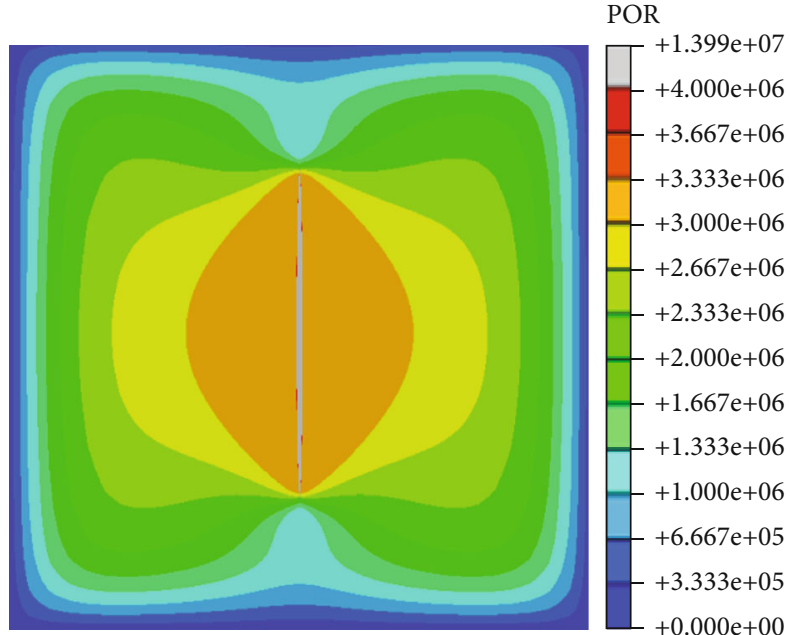

(b) Dilation angle $20^{\circ}$

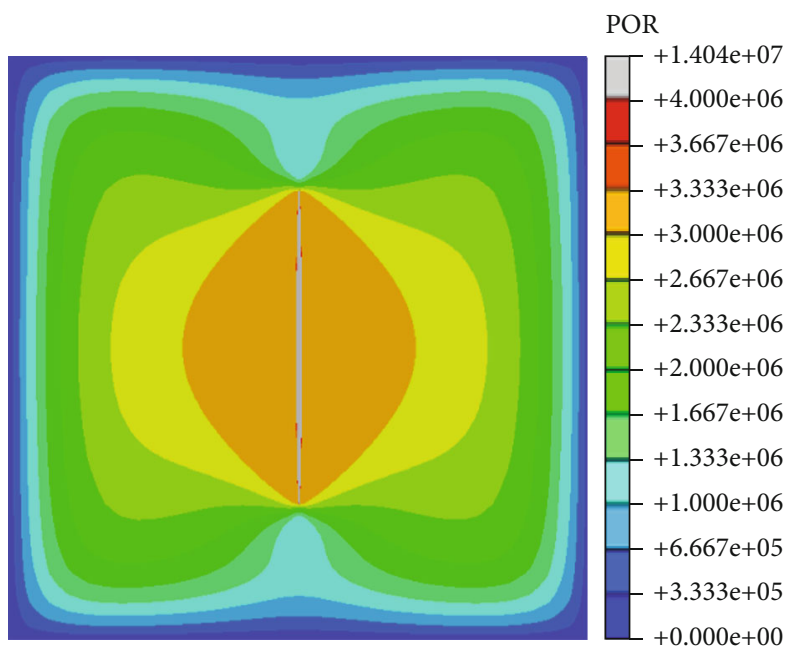

(c) Dilation angle $28^{\circ}$

Figure 20: Effect of dilation angle on pore pressure.

increases with friction angle decrease. When the friction angle decreases to $10^{\circ}$, fracture breakdown pressure and propagation pressure grow significantly, which leads to rapid increasing fracture width near the injection point. Figure 14 displays that the equivalent plastic strain area around the crack increases with the decreasing friction angle. Plastic strain occurs obviously at the fracture entrance with friction angle of $10^{\circ}$, which is difficult for crack to extent. Figures 15 and 16 present that pore pressure and stress in $x$ direction surround the fracture also increases with the decreasing friction angle.

Rocks with low friction angle are easy to occur plastic deformation and form wide and short crack.

4.3. Effect of Dilation Angle on Fracture Propagation. The dilation angle reflects the change rate of rock volume, normal displacement, and tangential displacement in the shearing process. To study the influence of dilation angle on hydraulic fracture propagation, the effects of dilation angle on fracture width and length, injection pressure, fracture width at the wellbore, equivalent plastic strain, pore pressure, and induced stress are simulated. It is assumed that the dilation angle of the rock is $10^{\circ}, 20^{\circ}$, and $28^{\circ}$, respectively, and friction angle is $28^{\circ}$. The other input parameters are the same as Section 4.2. The calculation results are presented in Figures 17-21.

Figure 17 demonstrates that crack width decreases with the increasing dilation angle, and this trend is not obvious. Figure 18 indicates that with injection time more than $20 \mathrm{~s}$, dilation angle has little influence on injection pressure and fracture width at the wellbore. Figure 19 displays that the equivalent plastic strain around the crack increases with the decrease of dilation angle, and the value of plastic strain is small. Figures 20 and 21 present that dilation angle has also little effect on pore pressure and stress on $x$ direction. Compared with friction angle, dilation angle is less sensitive to fracture width and length, as well as injection pressure. 


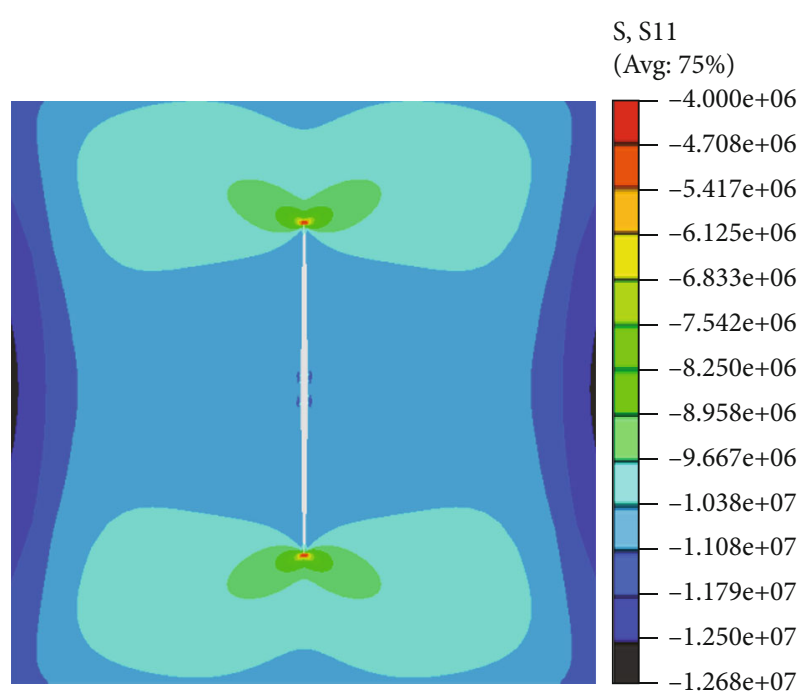

(a) Dilation angle $10^{\circ}$

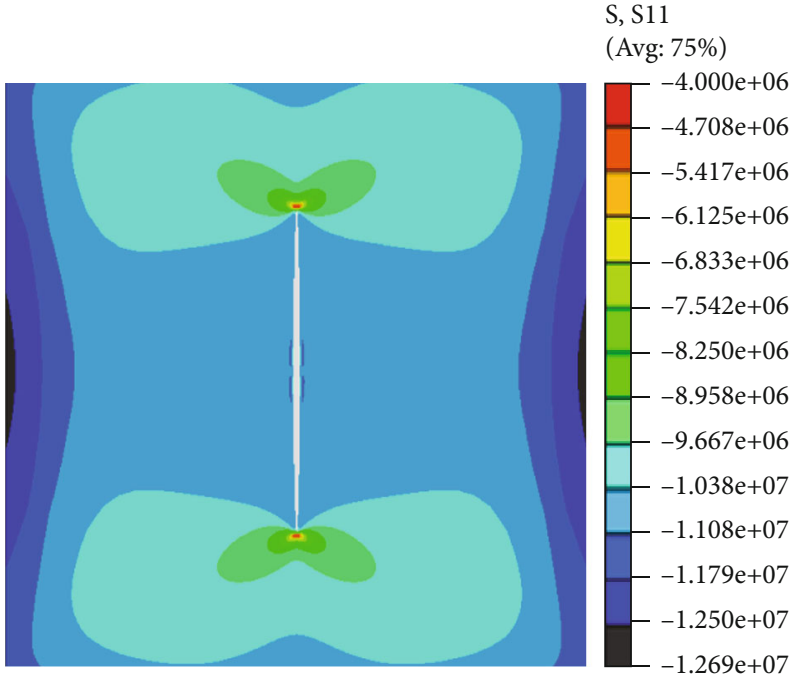

(b) Dilation angle $20^{\circ}$

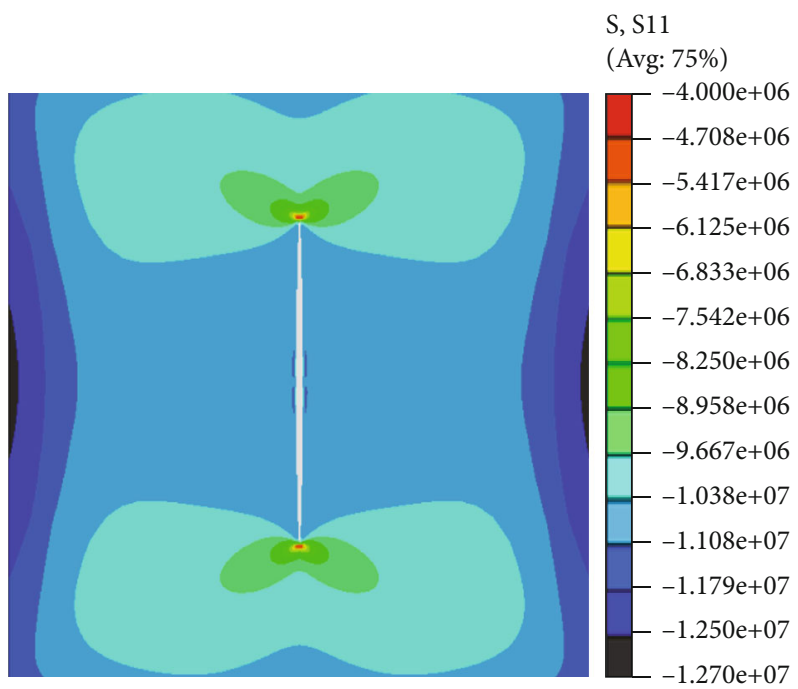

(c) Dilation angle $28^{\circ}$

FIGURE 21: Effect of dilation angle on stress on $x$ direction.

\section{Conclusions}

A fluid-solid coupling elastoplasticity fracture propagation model has been established. Effects of plasticity and damage with have been accounted. The extended finite element methods combined with cohesive zone are utilized to approach to model the fracture process in permeable rocks. The Abaqus 6.14 software has been used to investigate fracture propagation in elastoplastic formation. According to the above analysis, it can be concluded as follows:

(1) Calculation results by the model are compared with KGD model, and they have good agreements. It is suitable to simulate fracture propagation in fracturing treatment

(2) Compared with elastic formation, fracture propagation in elastoplastic formation is more difficult, the breakdown pressure and extending pressure are greater, and fracture shape is wider and shorter. Plastic deformation also leads to the fracture tip to be blunt. Plastic strain area grows with the increasing injection time, and the largest plastic strain appears near the fracture tip

(3) Fracture width increases, and fracture length decreases with the increasing stress difference. Under the condition of high stress difference or low friction angle, it is easy to occur large plastic deformation area, result in great breakdown pressure, propagation pressure, induced stress in $x$ direction, and pore pressure. Soft formations with great stress difference or low friction angle are inclined to form wide and short crack with blunt fracture tip

(4) Compared with friction angle, dilation angle is less sensitive to plastic deformation and fracture parameters. For the formation with high stress difference 
and friction angle, the influence of plasticity deformation on fracture propagation should not be ignored

\section{Data Availability}

The data used to support the findings of this study are included within the article.

\section{Conflicts of Interest}

The authors declare that they have no conflicts of interest.

\section{Authors' Contributions}

Yafei $\mathrm{Hu}$ and Jin Zhao contributed equally to this work and are co-first authors.

\section{Acknowledgments}

This work was supported by the financial support of the National Major Science and Technology Projects of China: the Fu Ling shale gas development demonstration project (2016ZX05060).

\section{References}

[1] Y. Hu, J. Zhao, J. Zhao et al., "Coiled tubing friction reduction of plug milling in long horizontal well with vibratory tool," Journal of Petroleum Science and Engineering, vol. 177, pp. 452-465, 2019.

[2] J. Zhao, X. Zhao, J. Zhao, L. Cao, Y. Hu, and X. Liu, "Coupled model for simulating proppant distribution in extending fracture," Engineering Fracture Mechanics, vol. 243, p. 107865, 2021.

[3] A. Dahi-Taleghani and J. E. Olson, "Numerical modeling of multistranded-hydraulic-fracture propagation: accounting for the interaction between induced and natural fractures," SPE Journal, vol. 16, no. 3, pp. 575-581, 2011.

[4] R. H. Dean and J. H. Schmidt, "Hydraulic-fracture predictions with a fully coupled geomechanical reservoir simulator," Spe Journal, vol. 14, no. 4, pp. 707-714, 2009.

[5] J. Geertsma and D. Klerk, "A rapid method of predicting width and extent of hydraulic induced fractures," Journal of Petroleum Technology, vol. 246, pp. 1571-1581, 1969.

[6] R. P. Nordgren, "Propagation of a vertical hydraulic fracture," Society of Petroleum Engineers Journal, vol. 12, no. 4, pp. 306314, 1972.

[7] T. K. Perkins and L. R. Kern, "Widths of hydraulic fractures," Society of Petroleum Engineers Journal, vol. 13, no. 9, pp. 937949, 1961.

[8] V. E. Saouma, M. L. Ayari, and D. A. Leavell, "Mixed mode crack propagation in homogeneous anisotropic solids," Engineering Fracture Mechanics, vol. 27, no. 2, pp. 171-184, 1987.

[9] R. K. Abu Al-Rub and G. Z. Voyiadjis, "On the coupling of anisotropic damage and plasticity models for ductile materials," International Journal of Solids and Structures, vol. 40, no. 11, pp. 2611-2643, 2003.

[10] B. Bohloli and C. J. de Pater, "Experimental study on hydraulic fracturing of soft rocks: influence of fluid rheology and confin- ing stress," Journal of Petroleum Science and Engineering, vol. 53, no. 1-2, pp. 1-12, 2006.

[11] M. Brünig, "Numerical simulation of the large elastic-plastic deformation behavior of hydrostatic stress-sensitive solids," International Journal of Plasticity, vol. 15, no. 11, pp. 12371264, 1999.

[12] S. Busetti, K. Mish, and Z. Reches, "Damage and plastic deformation of reservoir rocks: part 1. Damage fracturing," $A A P G$ bulletin, vol. 96, no. 9, pp. 1687-1709, 2012.

[13] S. Busetti, K. Mish, P. Hennings, and Z. Reches, "Damage and plastic deformation of reservoir rocks: part 2. Propagation of a hydraulic fracture," AAPG bulletin, vol. 96, no. 9, pp. 17111732, 2012.

[14] A. Shojaei, A. Dahi Taleghani, and G. Li, "A continuum damage failure model for hydraulic fracturing of porous rocks," International Journal of Plasticity, vol. 59, pp. 199-212, 2014.

[15] H. Sone and M. D. Zoback, "Visco-plastic properties of shale gas reservoir rocks," in Presented at the 45th U.S. Rock Mechanics/Geomechanics Symposium, San Francisco, California, USA, 2011.

[16] H. Wang, "Numerical modeling of non-planar hydraulic fracture propagation in brittle and ductile rocks using XFEM with cohesive zone method," Journal of Petroleum Science and Engineering, vol. 135, pp. 127-140, 2015.

[17] C. J. De Pater, Y. Dong, and B. Bohloli, "Experimental study of hydraulic fracturing in sand as a function of stress and fluid rheology," in Proceedings of the SPE Hydraulic Fracturing Technology Conference, College Station, Texas, USA, 2007.

[18] L. N. Germanovich, R. S. Hurt, J. A. Ayoub et al., "Experimental study of hydraulic fracturing in unconsolidated materials," in Proceedings of SPE International Symposium and Exhibition on Formation Damage Control, Lafayette, Louisiana, USA, 2012.

[19] E. Golovin, H. Jasarevic, A. Chudnovsky, J. W. Dudley, and G. K. Wong, "Observation and characterization of hydraulic fracture in cohesionless sand," in Proceedings of the 44th U.S. rock mechanics symposium and 5th U.S.-Canada rock mechanics symposium, Salt Lake City, Utah, 2010.

[20] Y. Omori, S. Jin, T. Ito, Y. Nagano, and K. Sekine, "Experimental study of hydraulic fracturing in unconsolidated sands using X-ray CT method," in Proceedings of the 47th U.S. Rock Mechanics/Geomechanics Symposium, San Francisco, California, 2013.

[21] D. B. Van Dam, P. Papanastasiou, and C. J. De Pater, "Impact of rock plasticity on hydraulic fracture propagation and closure," SPE Production \& Facilities, vol. 17, no. 3, pp. 149159, 2002.

[22] P. Papanastasiou, "The influence of plasticity in hydraulic fracturing," International Journal of Fracture, vol. 84, no. 1, pp. 61-79, 1997.

[23] P. Papanastasiou, "An efficient algorithm for propagating fluid-driven fractures," Computational Mechanics, vol. 24, no. 4, pp. 258-267, 1999.

[24] E. Sarris and P. Papanastasiou, "Modeling of hydraulic fracturing in a poroelastic cohesive formation," International Journal of Geomechanics, vol. 12, no. 2, pp. 160-167, 2012.

[25] K. S. Zaki, G. Wang, F. Meng, and A. S. Abou-Sayed, "A 3$\mathrm{D}$ plastic fracture simulation to assess fracture volumes in compacting reservoir," in Gulf Rocks 2004, the 6th North America Rock Mechanics Symposium (NARMS), OnePetro, 2004. 
[26] H. Wang, M. Marongiu-Porcu, and M. J. Economides, "Poroelastic and poroplastic modeling of hydraulic fracturing in brittle and ductile formations," SPE Production \& Operations, vol. 31, pp. 47-59, 2016.

[27] W. Z. Liu, J. Yao, and Q. D. Zeng, "Numerical simulation of hydraulic fracture propagation in deep reservior (in Chinese)," Scientia Sinica Technologica, vol. 49, no. 2, pp. 223-233, 2019.

[28] H. Lin, J. G. Deng, W. Liu, T. Xie, J. Xu, and H. L. Liu, "Numerical simulation of hydraulic fracture propagation in weakly consolidated sandstone reservoirs," Journal of Central South University, vol. 25, no. 12, pp. 2944-2952, 2018.

[29] K. Wu, Numerical Modeling of Complex Hydraulic Fracture Development in Unconventional Reservoirs, PhD Degree Dissertation, the University of Texas at Austin, Austin, Texas, 2014.

[30] J. Ma, G. Zhao, and N. Khalili, "A fully coupled flow deformation model for elasto-plastic damage analysis in saturated fractured porous media," International Journal of Plasticity, vol. 76, pp. 29-50, 2016.

[31] J. Zhao, J. Zhao, Y. Hu, S. Zhang, T. Huang, and X. Liu, "Numerical simulation of multistage fracturing optimization and application in coalbed methane horizontal wells," Engineering Fracture Mechanics, vol. 223, p. 106738, 2020.

[32] D. Lee, A Model for Hydraulic Fracturing and Proppant Placement in Unconsolidated Sands, PhD Degree Dissertation, the University of Texas at Austin, Austin, Texas, 2017.

[33] P. A. Vermeer and R. Borst, "Non-associated plasticity for soils, concrete and rock," Heron, vol. 29, no. 3, pp. 3-64, 1984.

[34] J. Zhao, J. Zhao, Y. Hu, T. Huang, X. Zhao, and X. Liu, "Nonplanar fracture propagation model for fluid-driven fracturing based on fluid-solid coupling," Engineering Fracture Mechanics, vol. 235, p. 107159, 2020.

[35] P. Menetrey and K. J. Willam, "Triaxial failure criterion for concrete and its generalization," ACI Structural Journal, vol. 99, pp. 311-318, 1995.

[36] Y. Yao, "Linear elastic and cohesive fracture analysis to model hydraulic fracture in brittle and ductile rocks," Rock Mechanics and Rock Engineering, vol. 45, no. 3, pp. 375-387, 2012.

[37] T. J. Boone and A. R. Ingraffea, "A numerical procedure for simulation of hydraulically-driven fracture propagation in poroelastic media," International Journal for Numerical and Analytical Methods in Geomechanics, vol. 14, no. 1, pp. 2747, 1990

[38] Z. Chen, A. P. Bunger, X. Zhang, and R. G. Jeffrey, "Cohesive zone finite element-based modeling of hydraulic fractures," Acta Mechanica Solida Sinica, vol. 22, no. 5, pp. 443-452, 2009.

[39] T. Elguedj, A. Gravouil, and A. Combescure, “Appropriate extended functions for X-FEM simulation of plastic fracture mechanics," Computer Methods in Applied Mechanics and Engineering, vol. 195, no. 7-8, pp. 501-515, 2006.

[40] M. G. Zielonka, K. H. Searles, J. Ning, and S. R. Buechler, "Development and validation of fully-coupled hydraulic fracturing simulation capabilities," in Presented at the 2014 SIMULIA Community Conference, Providence RI, 2014.

[41] G. T. Camacho and M. Ortiz, "Computational modelling of impact damage in brittle materials," International Journal of Solids and Structures, vol. 33, no. 20, pp. 2899-2938, 1996.

[42] V. Tvergaard and J. W. Hutchinson, "The relation between crack growth resistance and fracture process parameters in elastic-plastic solids," Journal of the Mechanics and Physics of Solids, vol. 40, no. 6, pp. 1377-1397, 1992.
[43] V. P. Nguyen, H. Lian, T. Rabczuk, and S. Bordas, "Modelling hydraulic fractures in porous media using flow cohesive interface elements," Engineering Geology, vol. 225, pp. 68-82, 2017.

[44] B. Sobhaniaragh, V. P. Nguyen, W. J. Mansur, and F. C. Peters, "Pore pressure and stress coupling in closely-spaced hydraulic fracturing designs on adjacent horizontal wellbores," European Journal of Mechanics-A/Solids, vol. 67, pp. 18-33, 2018.

[45] B. Sobhaniaragh, W. J. Mansur, and F. C. Peters, "The role of stress interference in hydraulic fracturing of horizontal wells," International Journal of Rock Mechanics and Mining Sciences, vol. 106, pp. 153-164, 2018.

[46] H. Y. Zhu, X. Zhao, J. Guo et al., "Coupled flow-stress-damage simulation of deviated-wellbore fracturing in hard-rock," Journal of Natural Gas Science and Engineering, vol. 26, pp. 711724, 2015.

[47] M. L. Benzeggagh and M. Kenane, "Measurement of mixedmode delamination fracture toughness of unidirectional glass/epoxy composites with mixed-mode bending apparatus," Composites science and technology, vol. 56, no. 4, pp. 439449, 1996.

[48] P. Valko and M. J. Economides, Hydraulic Fracture Mechanics, John Wiley \& Sons Ltd., Chichester, UK, 1995. 